\title{
CREB-Dependent Transcriptional Control and Quantal Changes in Persistent Long-Term Potentiation in Hippocampal Interneurons
}

\author{
Israeli Ran, ${ }^{1}$ Isabel Laplante, ${ }^{1}$ and Jean-Claude Lacaille ${ }^{1}$ \\ ${ }^{1}$ Groupe de Recherche sur le Système Nerveux Central (GRSNC) and Department of Physiology, Université de Montréal, Montreal, Quebec, Canada H3C 3J7
}

Mounting evidence indicates an important role of long-term synaptic plasticity in hippocampal inhibitory interneurons in learning and memory. The cellular and molecular mechanisms that underlie such persistent changes in synaptic function in interneurons remain, however, largely undetermined. A transcription- and translation-dependent form of long-term potentiation was uncovered at excitatory synapses onto hippocampal interneurons in oriens-alveus (OA-INs) which is induced by activation of type 1 metabotropic glutamate receptors $\left(\mathrm{cL}-\mathrm{LTP}_{\mathrm{mGluR1}}\right)$. Here, we use (1) a combination of pharmacological siRNA knock-down and overexpression approaches to reveal the molecular mechanisms of transcriptional control via cAMP response element-binding protein (CREB) during induction, and (2) quantal analysis to identify synaptic changes during maintenance of cL-LTP ${ }_{m G l u R 1}$ in rat hippocampus. Induction stimulated CREB phosphorylation in OA-INs via extracellular signal-regulated protein kinase (ERK) signaling. Also, CREB knockdown impaired cL$\mathrm{LTP}_{\mathrm{mGluR1}}$, whereas CREB overexpression facilitated the induction, demonstrating a necessary and permissive role of CREB via ERK signaling in transcriptional control in CL-LTP ${ }_{\text {mGluR1 }}$. Quantal analysis of synaptic responses during cL-LTP ${ }_{\text {mGluR1 }}$ maintenance revealed an increased number of quanta released, corresponding to enhanced transmitter release and a larger quantal size, indicating enhanced responsiveness to individual quanta. Fluctuation analysis of synaptic currents uncovered an increase in conductance and number of functional postsynaptic receptors contributing to single quanta. Our findings indicate that CREB-dependent transcription is a necessary permissive switch for eliciting persistent presynaptic and postsynaptic quantal changes at excitatory synapses in inhibitory local circuits, uncovering cell type-specific coupling of induction and expression mechanisms during persistent synaptic plasticity which may contribute to hippocampal long-term memory processes.

\section{Introduction}

Long-term synaptic plasticity in hippocampal pyramidal cells is associated with memory consolidation (Milner et al., 1998; Martin et al., 2000). Diverse types of inhibitory interneurons control hippocampal network activity (Klausberger and Somogyi, 2008) and long-lasting synaptic modifications in interneuron circuits have been implicated in hippocampal-dependent memory. Interneuron-selective mutation of the neurofibromatosis type 1 (NF1) gene increases interneuron extracellular signal-related kinase (ERK) signaling, enhances pyramidal cell inhibition, and impairs hippocampal long-term potentiation (LTP) and learning

Received Oct. 28, 2011; revised March 20, 2012; accepted March 21, 2012.

Author contributions: I.R., I.L., and J.-C.L. designed research; I.R. and I.L. performed research; I.R. and I.L. analyzed data; I.R., I.L., and J.-C.L. wrote the paper.

This work was supported by the Canadian Institutes of Health Research (operating grant to J.-C.L.; MOP-10848) and the Fonds de la Recherche en Santé du Québec (FRSQ; Groupe de Recherche sur le Système Nerveux Central). J.-C.L is the recipient of the Canada Research Chair in Cellular and Molecular Neurophysiology and I.R. is the recipient of a Fellowship of the Savoy Foundation. We wish to thank Dr. W.S. Sossin for comments on the manuscript. GAD67-GFP mice were kindly provided by Y. Yanagawa, K. Obata, and L. Mei. CREB plasmids were kindly provided by S. Josselyn.

Correspondence should be addressed to Dr. Jean-Claude Lacaille, Département de Physiologie, Faculté de Médecine, Université de Montréal, Case Postale 6128, Succursale Centre-ville, Montréal, Quebec, Canada, H3C $3 J 7$. E-mail: jean-claude.lacaille@umontreal.ca.

I. Ran's present address: Department of Molecular and Cellular Physiology, Stanford University, Stanford, CA 94305. DOI:10.1523/JNEUROSCI.5463-11.2012

Copyright $\odot 2012$ the authors $\quad 0270-6474 / 12 / 326335-16 \$ 15.00 / 0$
(Cui et al., 2008). Moreover, spatial learning triggers interneuron ERK signaling and increases pyramidal cell inhibition, implicating plasticity of inhibition in constraining hippocampal LTP and learning (Cui et al., 2008), as previously suggested with network simulation studies (Grunze et al., 1996). Hippocampal-dependent learning also triggers long-lasting structural plasticity at excitatory mossy fiber synapses onto CA3 interneurons which is required for precision of memory and learned behavior (Ruediger et al., 2011). However, the synaptic mechanisms underlying learning-related, long-lasting interneuron plasticity remain largely unknown.

Glutamatergic synapses onto hippocampal interneurons display multiple forms of long-lasting plasticity (Kullmann and Lamsa, 2007; McBain and Kauer, 2009), but these typically last 30 min and their implication in learning-dependent plasticity remains unclear. Recently, a late-phase LTP (L-LTP), lasting $24 \mathrm{~h}$, was uncovered at synapses onto oriens-alveus interneurons (OAINs) that are induced by repeated activation of type 1 metabotropic glutamate receptors (chemical mGluR1-mediated late LTP; cL-LTP ${ }_{\text {mGluRI }}$ ) (Ran et al., 2009), which requires ERK signaling and is transcription and translation dependent (Ran et al., 2009). By analogy to pyramidal cell L-LTP (Abel et al., 1997), cL-LTP ${ }_{\text {mGluR } 1}$ is an interesting candidate mechanism for learning-related, long-term synaptic plasticity in interneurons.

mTOR signaling via ERK regulates cap-dependent translation during cL-LTP ${ }_{\text {mGluR1 }}$ induction (Ran et al., 2009), indicating that 
translational control mechanisms during synaptic plasticity in interneurons are similar to those in pyramidal cells (Banko et al., 2005) and conserved across cell types. Mechanisms regulating transcription during $\mathrm{cL}-\mathrm{LTP}_{\mathrm{mGluR} 1}$ remain undetermined. In pyramidal cells, transcriptional control of plasticity-related genes engages a tightly regulated $\mathrm{Ca}^{2+}$ - and ERK-dependent signaling cascade from synapse to nucleus to activate cAMP response element-binding protein (CREB) triggering transcription of CRErelated genes (West et al., 2002). Interfering with CREB expression impairs hippocampal L-LTP and memory (Bourtchuladze et al., 1994), whereas de-repression of CREB-dependent transcription facilitates them (Lee and Silva, 2009). Whether similar transcriptional control mechanisms are conserved during interneuron synaptic plasticity remains unknown.

Changes in evoked and miniature synaptic currents during $\mathrm{cL}-L T P_{\mathrm{mGluR1}}$ in interneurons implicate presynaptic and postsynaptic maintenance mechanisms (Ran et al., 2009). In pyramidal neurons, quantal analysis indicated a presynaptic increase in the number of quanta released with unchanged postsynaptic response to individual quanta during L-LTP (Bolshakov et al., 1997), suggesting that synaptic locus of persistent plasticity may differ across cell types.

Here we combine pharmacological, molecular biological, quantal, and fluctuation analyses to uncover a necessary and permissive role of CREB via ERK in transcriptional control during induction, leading to an enhancement of transmitter release and increase in channel conductance and number of functional postsynaptic receptors during maintenance of interneuron persistent synaptic plasticity.

\section{Materials and Methods}

Slice cultures. Hippocampal slice cultures were prepared from 7- to 9-dold Sprague Dawley rats of either sex, as previously described (Bourdeau et al., 2007). All experiments were performed in accordance with the animal care guidelines of the Canadian Council of Animal Care with the approval of the Ethics Committee at Universite de Montréal. Briefly, brains were removed and dissected in HBSS-based medium (Invitrogen). Subsequently, cortico-hippocampal slices (400 $\mu \mathrm{m}$ thick) were cut using a McIlwain tissue chopper (Mickle Laboratory Engineering). Following dissection, slices were positioned on Millicell culture plate inserts (Millipore) and recovered for $24 \mathrm{~h}$ in OptiMEM (Invitrogen) at $37^{\circ} \mathrm{C}$ in a humidified atmosphere ( $95 \%$ air, $\left.5 \% \mathrm{CO}_{2}\right)$. Slices were then placed in a Neurobasal medium (Invitrogen) supplemented with B27 and Glutamax I (Invitrogen) for 3-7 d.

Gene-gun transfection. cDNA and siRNA were biolistically transfected in organotypic slice cultures (4-6 d in vitro) using a Helios gene gun (Bio-Rad) following the manufacturer's instructions and as previously described (Bourdeau et al., 2007). Gold beads $(1.6 \mu \mathrm{m})$ were coated with $50 \mu \mathrm{g}$ yellow-fluorescent protein (YFP) cDNA and $160 \mu \mathrm{l}$ of $20 \mu \mathrm{M}$ duplex smart pool siRNA that was targeted to rat CREB (NM 031017; siCREB). A nontargeting siRNA (commercially labeled as siCONTROL) cotransfected with YFP plasmid was used as control (siCtl). Some transfected slices were fixed with $4 \%$ paraformaldehyde (PFA) at $48 \mathrm{~h}$ after transfection and used for immunofluorescence as described below. All siRNAs were purchased from Dharmacon.

pcDNA3-CREB-GFP vector was obtained by extracting CREB-GFP sequence from $\mathrm{pHSV}$-CREB-GFP (kindly provided by Dr. Sheena Josselyn, Hospital for Sick Children, Toronto, Ontario, Canada; Han et al., 2007) with HindIII and EcoRI restriction enzymes and inserted into pcDNA3. For CREB expression experiments, $50 \mu \mathrm{g}$ of pcDNA3-CREBGFP or control GFP vector (pcDNA3-GFP10; Bourdeau et al., 2007) was coated onto beads and transfected.

$c L-L T P_{m G l u R 1}$ induction and whole-cell recordings. At $48 \mathrm{~h}$ posttransfection, slices received a chemical induction protocol (sham, single, or repeated mGluR1 stimulation) as previously described (Ran et al., 2009). The chemical induction protocol consisted of three applications
(10 min duration each at $30 \mathrm{~min}$ intervals) of the mGluR1/5 agonist (S)-3,5-dihydroxyphenylglycine (DHPG; $5 \mu \mathrm{M}$, Tocris Bioscience) in the presence of the mGluR5 antagonist 2-methyl-6-(phenylethynyl)pyridine (MPEP; $25 \mu \mathrm{M}$, Ascent Scientific). For treatment with inhibitors or antagonists, drugs were applied from $30 \mathrm{~min}$ before to $30 \mathrm{~min}$ after DHPG/MPEP treatment. DL-2-amino-5-phosphonovaleric acid (AP-5) and 1-trimethyl-ammonio-5-(1-adamantane-methylammoniopentane) dibromide (IEM-1460) were purchased from Tocris Bioscience, tetrodotoxin (TTX) was obtained from Alomone Labs, and actinomycin D and U0126 were purchased from Calbiochem. Slices recovered for a $24 \mathrm{~h}$ period before recordings.

After the $24 \mathrm{~h}$ recovery period, slices were transferred to oxygenated artificial cerebrospinal fluid (ACSF) at room temperature containing the following (in mM): $124 \mathrm{NaCl}, 2.5 \mathrm{KCl}, 1.25 \mathrm{NaH}_{2} \mathrm{PO}_{4}, 4 \mathrm{MgSO}_{4}, 4 \mathrm{CaCl}_{2}$, $26 \mathrm{NaHCO}_{3}$, and $10 \mathrm{D}-(+)$-glucose (pH 7.35-7.45; 295-305 mOsmol) and maintained for at least $45 \mathrm{~min}$ before electrophysiological recordings. Experimenters were blind to all treatment groups. CA3 and CA1 regions were disconnected by a surgical cut. Slices were transferred to the recording chamber, maintained submerged, and continuously perfused $(2-3 \mathrm{ml} / \mathrm{min})$ with oxygenated ACSF at $31 \pm 0.5^{\circ} \mathrm{C}$. OA-INs were identified based on their soma shape and position in stratum oriens using an upright microscope (Nikon Eclipse E600FN) equipped with a long-range water-immersion objective $(40 \times$; Nomarski Optics) and an infrared camera (4980 Series; Cohu). Whole-cell patch-clamp recordings were obtained from OA-INs using borosilicate pipettes $(3-6 \mathrm{M} \Omega$ ) filled with a solution containing the following (in mM): $135 \mathrm{CsMeSO}_{3}, 10$ phosphocreatine, $5 \mathrm{NaCl}, 10 \mathrm{HEPES}, 1 \mathrm{MgCl}_{2}, 0.1$ spermine, 2 QX-314, 2 ATPTris, 0.4 GTP-Tris, and $0.1 \%$ biocytin (pH 7.2-7.3; 280-290 mOsmol). Recordings were made in the voltage-clamp mode using a Multiclamp 700A amplifier (Molecular Devices). The cells holding potential were maintained at $-60 \mathrm{mV}$ and series resistance was routinely monitored. Recorded signals were low-pass filtered at $2 \mathrm{kHz}$, digitized at $20 \mathrm{kHz}$, and stored on a PC. Data acquisition and off-line analyses were performed using the 1322A Digidata acquisition board and pClamp 9.0-9.2 (Molecular Devices) and Origin 7.5 (Origin Lab) software. Data were only included if the holding current was stable or if series resistance varied $<25 \%$ of initial value. In CREB- and GFP-expression experiments, electrophysiological recordings were performed from a GFP-expressing transfected OA-IN and from an untransfected OA-IN in the same slice.

Evoked and miniature EPSCs. Minimal stimulation was used to evoke putative single-fiber EPSCs as previously described (Perez et al., 2001; Lapointe et al., 2004). EPSCs mediated by non-NMDA receptors were recorded in the presence of AP-5 (50 $\mu \mathrm{M})$ and GABAzine ( $5 \mu \mathrm{M})$ to block $\mathrm{NMDA}$ and $\mathrm{GABA}_{\mathrm{A}}$ receptors, respectively. EPSC pairs were evoked by constant current pulses (50 $\mu$ s duration, $50 \mathrm{~ms}$ interpulse interval, 0.5 $\mathrm{Hz}$ ) using a bipolar theta-glass electrode filled with ACSF and placed in the stratum oriens. At the onset of each experiment, the stimulus strength was first gradually increased until all-or-none responses were consistently observed and, subsequently, it was carefully readjusted to a value which yielded $\sim 50 \%$ successes (range $40-60 \%$ ) of all-or-none responses. The criteria for EPSC evoked by minimal stimulation included an invariant latency, amplitude, and failure rate insensitive to $\pm 5 \%$ alterations in stimulus intensity, and lower stimulation intensities yielding failures only (Perez et al., 2001; Lapointe et al., 2004). The amplitude of average EPSC (including failures), failure rate (number of failures as percentage of total number of stimulations), and potency (amplitude of EPSCs excluding failures) was calculated from 5 min bins over a $10-20$ min period. Because failure rate was a parameter adjusted by the experimenter, EPSC potency was used to monitor amplitude changes in evoked transmission. As LTP alters presynaptic release, the stimulation intensity which evoked EPSCs with minimal stimulation was significantly reduced $\left(\sim 39 \%\right.$ reduction) in cells with $\mathrm{cL}-\mathrm{LTP}_{\mathrm{mGluR} 1}$ (minimal stimulation strength was $297 \pm 63 \mu \mathrm{A}$ in sham $[n=10]$ and $181 \pm 22 \mu \mathrm{A}$ in $3 \times$ DHPG/MPEP-treated group [ $n=17$ ], $p<0.05$, unpaired $t$ test). Non-NMDA EPSC rectification ratio was measured as the ratio of peak EPSC amplitude at +40 and $-60 \mathrm{mV}$, in the presence of AP-5. For measurement of NMDA/non-NMDA receptor ratio of EPSCs, the NMDA component was measured as the EPSC amplitude $40 \mathrm{~ms}$ after the stimulus artifact at $+40 \mathrm{mV}$ in absence of AP-5, and the non-NMDA 
component was measured at the peak of the EPSC at $-60 \mathrm{mV}$ in AP-5. In both cases (rectification and NMDA/non-NMDA ratio), EPSCs were evoked at $2 \times$ minimal stimulation threshold, at which no failures were observed.

Spontaneous miniature EPSCs (mEPSCs) were recorded after further addition of TTX $(1 \mu \mathrm{M})$. mEPSCs were detected with a running template (average of 20 events) which had a well characterized baseline, using pClamp 9 software. The threshold for mEPSC detection was set at $3 \mathrm{pA}$ and a minimum of 250 events were sampled per neuron over a $15-25 \mathrm{~min}$ period.

EPSC amplitude histogram analysis. To estimate quantal changes in synaptic transmission, we performed an analysis of unitary EPSC amplitude histogram fit by multiple Gaussian functions (Redman, 1990; Bolshakov et al., 1997) using subsets of recordings obtained in previous experiments (Ran et al., 2009). The data subsets were chosen based on strict criteria for stationary recording conditions (stable series resistance, membrane resistance, and holding current; no trend in EPSC amplitude and failure rate over time) during the period necessary to collect large samples of synaptic events $(n=300-500)$ evoked by minimal stimulation, and were used for quantal analysis. Unbinned amplitude histograms were first constructed from unitary EPSCs evoked by minimal stimulation during 10-20 min recording periods (Bolshakov et al., 1997). Upon binning (1 pA bin size), histogram plots were sequentially fitted by incrementing Gaussian functions in a maximum likelihood manner. At first, a single Gaussian function was used to fit baseline noise sampled from failed responses, yielding a near zero mean and SD. Amplitude histograms of successful EPSCs were then fitted by the sum of $n+$ 1 Gaussian functions, constrained to SD values obtained from the Gaussian used for fitting baseline noise.

The sum of Gaussian function used to fit successful EPSCs was as follows:

$$
\sum_{k=1}^{n} \frac{a_{k}}{\sigma_{k} \sqrt{2 \pi}} e^{-\left(x_{j}-\mu_{k}\right)^{2} / 2 \sigma_{k}^{2}}
$$

where $x_{j}$ is the amplitude of the $j$ th EPSC, $\mu_{k}$ is the mean amplitude, and $a_{k}$ is the area under the $k t h$ Gaussian component. $\sigma_{k}^{2}$ was estimated based on the assumption that quantal variance increased linearly with the total number of quanta according to ${\sigma_{k}}^{2}=\sigma_{n}{ }^{2}+k \cdot \sigma_{q}{ }^{2}$ where ${\sigma_{n}}^{2}$ is the baseline noise variance and $\sigma_{q}{ }^{2}$ is the quantal variance. Both the mean amplitude, $\mu_{k}$, and the area under the Gaussian fit, $a_{k}$, were not constrained.

Nonstationary fluctuation analysis. Peak-scaled nonstationary fluctuation analysis of mEPSCs was performed as described previously (Hartveit and Veruki, 2007), using subsets of recordings obtained in previous experiments (Ran et al., 2009). Data subsets were selected based on their stationary recording conditions (stable series resistance, membrane resistance, and holding current; $<15 \%$ variation in mEPSC amplitude, rise and decay times over time) during the period necessary to collect a large sample of mEPSCs $(n=350-500)$. Peak scaling was employed in the nonstationary noise analysis to compensate for quantal variability (both in quantal size and number of quanta) in mEPSCs in OA-INs (Hartveit and Veruki, 2007). Fluctuations of individual mEPSC events about their peak-scaled mean response are used to estimate single-channel properties from variance-mean plots. For each cell, all events were first aligned to the point of steepest rise (maximum point of derivative). Subsequently, the group mean was calculated for each point in the trace, scaled to peak of each individual mEPSC, and subtracted from the entire mEPSC trace to obtain the difference current. The variance of difference currents was then plotted against time and subsequently against the mean mEPSC, yielding a variance mean plot (Hartveit and Veruki, 2007).

We used the following equations (Hartveit and Veruki, 2007) to obtain the mean and variance from $n$ mEPSC events each with $m$ sample points:

$$
\operatorname{Mean}(i)=\frac{1}{n} \sum_{j=1}^{n} x(i)_{j}, i=1, \ldots, m,
$$

$i$ being the index for the sampled point $(1, \ldots, m)$ and $j$ corresponding to the individual mEPSC event $(1, \ldots, n) . m$ included all points within a 25 ms window encompassing an mEPSC event which at $20 \mathrm{kHz}$ sampling rate yielded 500 points per event. The ensemble variance about each point $(i)$ is described by the following:

$$
\operatorname{Var}(i)=\frac{1}{n-1} \sum_{j=1}^{n}\left[x(i)_{j}-\operatorname{Mean}(i)\right]^{2}, i=1, \ldots, m .
$$

The above equations were used for obtaining the variance and mean for each point in the trace and for constructing a variance-mean plot. The variance-mean plot was then fitted with a parabola corresponding to the following equation:

$$
\sigma^{2}(I)=i_{S C} \cdot I-\frac{I^{2}}{N}+\sigma_{\text {noise }}^{2},
$$

where $\sigma^{2}(I)$ is the current variance ( $\sigma$ for standard deviation), $i_{S C}$ is the single-channel current, and $N$ the total number of activated channels $\left(\sigma^{2}\right.$ noise being the background noise variance). The singlechannel conductance ( $\gamma$, or chord conductance) is calculated according to: $\gamma=i_{S C} /\left(V_{m}-E_{r}\right)$, using the holding potential $\left(V_{\mathrm{m}}\right)$ and reversal potential $\left(E_{\mathrm{r}}\right)$ for EPSCs.

GAD67-GFP mice and immunofluorescence. Heterozygous GAD67GFP knock-in mice of either sex were genotyped as originally described (Tamamaki et al., 2003). In brief, DNA was extracted from the tails with the DNeasy tissue kit (Qiagen) in accordance with the manufacturer's instructions. PCR was used to amplify the DNA $\left(68^{\circ} \mathrm{C}, 3 \mathrm{~min}\right.$ for 30 cycles) on an iCycler (Bio-Rad) using forward primer $5^{\prime}$-GGCAC AGCTCTCCCTTCTGTTTGC-3' and reverse primer 5' -CTGCTTGTCG GCCATGATATAGACG-3' (Alpha DNA). PCR products were visualized on $1.5 \%$ agarose gel containing $2 \mu \mathrm{g} / \mathrm{ml}$ ethidium bromide. GAD67GFP mice (17-22 d old) were deeply anesthetized with sodium pentobarbital (MTC Pharmaceuticals) and perfused transcardially with ice-cold ACSF containing the following (in $\mathrm{mm}$ ): 110 choline-chloride, $2.5 \mathrm{KCl}, 7 \mathrm{MgCl}_{2}, 26 \mathrm{NaHCO}_{3}, 7$ dextrose, 1.3 ascorbic acid, and 0.5 $\mathrm{CaCl}_{2}$ and saturated with $95 \% \mathrm{O}_{2}$ and $5 \% \mathrm{CO}_{2}$. Coronal hippocampal slices (300 $\mu \mathrm{m}$ thick) were obtained using a vibratome (Leica VT 10005) and transferred to normal oxygenated ACSF containing the following (in mM): $124 \mathrm{NaCl}, 2.5 \mathrm{KCl}, 1.25 \mathrm{NaH}_{2} \mathrm{PO}_{4}, 2 \mathrm{MgCl}_{2}, 2 \mathrm{CaCl}_{2}, 26 \mathrm{NaHCO}_{3}$, $10 \mathrm{D}-(+)$-glucose, and 1.3 ascorbic acid maintained at $31-33^{\circ} \mathrm{C}$. After a one hour recovery period, slices were treated, fixed with $4 \%$ PFA at 0,30 , or $60 \mathrm{~min}$ after treatment and re-sectioned as described previously (Perez et al., 2001; Ran et al., 2009). Sections were permeabilized with $0.3 \%$ Triton X-100 in PBS (15 min) and unspecific binding was blocked with $10 \%$ normal goat serum in $0.1 \%$ Triton X-100/PBS $(1 \mathrm{~h})$. Rabbit polyclonal phospho-CREB ${ }^{\text {(S133) }}$ antibody (1:500; Millipore) was incubated overnight at $4^{\circ} \mathrm{C}$. Sections were subsequently incubated at room temperature with Texas-Red-conjugated goat anti-rabbit IgG (1:600; 90 min, Jackson ImmunoResearch ). Images were acquired using a confocal microscope (LSM510; Zeiss) at excitation wavelengths of 488 and $543 \mathrm{~nm}$. Images from different treatment/groups were acquired using the exact same parameters. Cell fluorescence was quantified using ImageJ software (National Institutes for Health) by comparing integrated density in cells corrected for background. Only cells expressing nuclear phospho-CREB were quantified. In initial control experiments, the CREB phosphorylation level was examined in interneurons in slice cultures and found to be highly variable, whereas basal phosphorylation level was more constant in acute slices. Thus, phospho-CREB immunolabeling experiments were performed on acute slices.

For immunofluorescence and siRNA experiments, cultured slices were permeabilized with $0.6 \%$ Triton X-100 in PBS (15 min) and immunolabeled as described above using rabbit monoclonal CREB antibody (1: 4000; Cell Signaling Technology) and Texas-Red-conjugated goat antirabbit IgG (1:300). CREB expression was quantified in YFP-positive cells in the CA1 region. YFP-expressing OA-INs were distinguished from pyramidal neurons based on their soma location (OA vs pyramidal layer) and dendritic morphology (including absence vs presence of spines). For example, pyramidal-shaped cells with spiny dendrites were considered 
pyramidal cells and multipolar or bipolar cells with horizontally oriented dendrites in OA (sometimes sparsely spiny) were considered OA-INs. Confocal parameters were set using siCtl-treated slices and immunofluorescence was quantified using integrated density (as described above). Values in siCREB-transfected YFP-expressing cells were compared with siCtl-transfected YFP-expressing cells, since biolistic delivery of siRNA and plasmid in the cytoplasm of neurons may result in siRNA knockdown of CREB without expression of YFP (because YFP plasmid requires nuclear delivery for expression).

HEK293 cell transfection and Western blotting. HEK293 cells were grown in DMEM supplemented with $10 \%$ fetal bovine serum, $100 \mathrm{U} / \mathrm{ml}$ penicillin, $100 \mu \mathrm{g} / \mathrm{ml}$ streptomycin, and $1 \mathrm{~mm} \mathrm{~L}$-glutamine (Wisent) and maintained at $37^{\circ} \mathrm{C}$ in $5 \% \mathrm{CO}_{2}$ humidified atmosphere. Approximately 150,000 cells were seeded in $35 \mathrm{~mm}$ tissue culture dishes. Cells were transfected during $48 \mathrm{~h}$ with pcDNA3-GFP10 or pcDNA3-CREB-GFP with Fugene 6, according to the manufacturer's instructions (Roche). Following transfection, cells were incubated for $2 \mathrm{~h}$ in serum-free medium and then received a 15 min treatment with $50 \mu \mathrm{m}$ forskolin (FSK; Alomone Labs) or vehicle (dimethylsulfoxide; DMSO). Following treatment, cells were lysed with a buffer $(150 \mathrm{~mm} \mathrm{NaCl}, 50 \mathrm{~mm}$ Tris- $\mathrm{HCl}, \mathrm{pH}$ 7.4, 2 mм EDTA, 2 mм NaF, $2 \mathrm{~mm} \mathrm{Na}_{3} \mathrm{VO}_{4}, 1 \%$ Triton X-100, 0.5\% deoxycholate, and $0.1 \%$ SDS) containing protease inhibitors (Inhibitor Cocktail Set I from Calbiochem). The cell lysate was centrifuged $\left(19,000 \times g, 20 \mathrm{~min}, 4^{\circ} \mathrm{C}\right)$ and the resultant supernatant was collected and analyzed for protein content using bicinchoninic acid assay (Pierce). Protein extracts $(25 \mu \mathrm{g})$ were resolved on 12\% SDS-PAGEs and transferred onto polyvinylidene difluoride membranes. Immunoblotting was performed using phospho-CREB and CREB antibodies as for immunofluorescence (1:1000; overnight at $\left.4^{\circ} \mathrm{C}\right)$. Immunoreactive bands were detected using horseradish peroxidase-conjugated anti-rabbit IgGs (1:20,000; Jackson ImmunoResearch) followed by enhanced chemiluminescence detection (PerkinElmer). Immunoreactive bands were scanned with a desktop scanner and densitometric analysis was done using Quantity One software (Bio-Rad). Phosphorylated-CREB (pCREB) and CREB levels were assessed in FSK and DMSO (vehicle)treated groups. pCREB values were normalized to total CREB protein levels, and pCREB/CREB ratios in FSK-treated groups were expressed as the percentage of values in DMSO control groups.

Quantitative single-cell RT-PCR. OA-INs were visualized in slice cultures using infrared differential interference contrast (DIC) optics as described above. For cell harvest, micropipettes were pulled from standard patch-clamp borosilicate glass capillaries $(1.5 / 0.84 \mathrm{~mm}$; WPI). At 30-60 min following $3 \times$ DHPG/MPEP treatment, single OA-INs were harvested using gentle negative pressure into a micropipette $(\sim 8-10 \mu \mathrm{m}$ tip diameter) filled with $4-6 \mu$ l of ACSF. Subsequently, cells were lysed in $10 \mu \mathrm{l}$ of iScript RT-qPCR Sample Preparation Reagent (Bio-Rad) and their mRNA isolated according to the manufacturer's instructions. Three to four cells were individually collected in each condition and pooled for further quantitative PCR analysis (Durand et al., 2006). Reactions with reverse-transcriptase were performed on an iCycler (Bio-Rad) with the iScript cDNA synthesis kit (Bio-Rad) according to the manufacturer's instructions. cDNA obtained from each cell was pooled and the resulting mix was subjected to quantitative PCR analysis on a DNA Engine Opticon 2 (Bio-Rad) by using IQ Supermix (Bio-Rad) according to the manufacturer's instructions. Briefly, $10 \mu \mathrm{l}$ of cDNA was added to $0.2 \mu \mathrm{M}$ primers and $25 \mu \mathrm{l}$ of IQ mix and adjusted to a final volume of $50 \mu \mathrm{l}$. Samples were amplified under the following temperature conditions: 3 min at $94^{\circ} \mathrm{C}$ and 50 cycles of $93^{\circ} \mathrm{C}$ for $30 \mathrm{~s}, 60^{\circ} \mathrm{C}$ for $30 \mathrm{~s}$, and $72^{\circ} \mathrm{C}$ for $30 \mathrm{~s}$. A melting curve from $55-95^{\circ} \mathrm{C}$ was carried out to improve the sensitivity and specificity of amplification reactions. Two different sets of c-fos primers were used: Primer \#1 (62 bp), forward: $5^{\prime}$-GAGCCCTCCTCTGACTCACT GA-3', reverse: 5'-TGCCTTCTCTGACTGCTCACA-3'; Primer \#2 (212 bp), forward: 5'-ACCATGATGTTCTCGGGTTTCAA-3', reverse: 5'GCTGGTGGAGATGGCTGTCAC-3'; and GAPDH was used as a housekeeping gene (123 bp), forward: 5' -AGGTCGGTGTGAACGGATTTG-3', reverse: 5'-TGTAGACCATGTAGTTGAGGTCA-3'. To verify specificity and ensure no contamination by genomic DNA (gDNA), the resulting product was loaded on $1.2 \%$ agarose gel. The difference in molecular weight products was easily distinguishable between mRNA and gDNA. In addition, cell identity of the pooled cDNA was confirmed by PCR using GAD67 (400 bp), forward: 5'-TTTGGATATCATTGGTTTAGCTGGCGAAT-3', reverse: 5'-TTTTTGCCTCTAAATCAGCCGGAATTATCT-3'. Data were analyzed with Opticon 3 software (Bio-Rad) following the $2^{-\Delta \Delta C T}$ method where treated groups were compared with a sham control group.

Statistical analysis. Between groups comparisons were performed using an unpaired Student's $t$ test or ANOVA followed by post hoc Tukey's test as suitable. Values were expressed as mean \pm SEM and a $p$ value $<0.05$ was considered significant.

\section{Results}

\section{Induction of cL-LTP ${ }_{\text {mGluR1 }}$}

Repeated activation of mGluR1 by treatment of hippocampal slice cultures with the mGluR1/5 agonist DHPG in the presence of the mGluR5 antagonist MPEP elicits a persistent long-term potentiation (cL-LTP ${ }_{\text {mGluR } 1}$ ) lasting at least $24 \mathrm{~h}$ at OA-IN excitatory synapses (Fig. 1). As previously reported (Ran et al., 2009), $\mathrm{cL}_{-} \mathrm{LTP}_{\mathrm{mGluR} 1}$ is manifested at $24 \mathrm{~h}$ postinduction as a $205 \pm 41 \%$ increase in the potency of EPSCs evoked by minimal stimulation, as well as a $46 \pm 5 \%$ decrease in paired-pulse ratio (PPR), relative to sham treatment (Fig. 1). Prior establishment of cL-LTP ${ }_{\text {mGluR }}$ was shown to occlude subsequent induction of Hebbian mGluR1mediated early phase LTP by pairing theta-burst stimulation with postsynaptic depolarization in OA-INs (Ran et al., 2009). We examined further the relation between $\mathrm{CL}_{-} \mathrm{LTP}_{\mathrm{mGluR} 1}$ and Hebbian LTP in OA-INs by determining if action potential activity was required during induction of $\mathrm{cL}-\mathrm{LTP}_{\mathrm{mGluR} 1}$. Treatment of slice cultures with TTX $(1 \mu \mathrm{M})$ during repeated mGluR1 stimu-

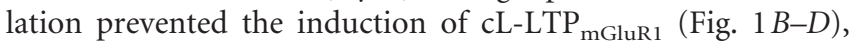
indicating a requirement for action potential firing during CLLTP $_{\text {mGluR1 }}$ induction. Next we tested if $\mathrm{cL}^{-L T P} \mathrm{mGluR}_{\mathrm{m}}$ induction required NMDA receptor activation. Application of the NMDA receptor antagonist AP-5 during repeated mGluR1 stimulation did not block the induction of $\mathrm{cL}^{-\mathrm{LTP}_{\mathrm{mGluR} 1}}$ (182 $\pm 38 \%$ increase in potency and $40 \pm 6 \%$ decrease in PPR in $3 \times$ DHPG/ $\mathrm{MPEP}+\mathrm{AP}-5$ treatment relative to AP-5 alone; Fig. $1 B-D)$. Together these results indicate that induction of $\mathrm{CL}^{-\mathrm{LTP}_{\mathrm{mGluR} 1}}$ at OA-IN excitatory synapses is independent of NMDA receptors and requires action potential firing for induction; these properties are also shared by the Hebbian form of early LTP at these synapses (Perez et al., 2001; Lapointe et al., 2004).

\section{CREB activation is necessary for $\mathrm{CL}-\mathrm{LTP}_{\text {mGluR1 }}$}

Since cL-LTP ${ }_{\text {mGluR1 }}$ requires the translation of newly transcribed mRNAs (Ran et al., 2009), we next investigated the mechanisms regulating transcription during the establishment of cL$\mathrm{LTP}_{\mathrm{mGluR} 1}$. CREB-dependent transcriptional control is critical for long-term synaptic changes and memory (Kaang et al., 1993; Bourtchuladze et al., 1994; Yin and Tully, 1996; Tully et al., 2003). Therefore we investigated its role in persistent long-term potentiation in interneurons. Also, since ERK signaling is implicated in many transcriptional control pathways including CREB-dependent pathways (Impey et al., 1998), and ERK is involved in cL-LTP ${ }_{\text {mGluR1 }}$ induction (Ran et al., 2009), we examined the role of ERK in transcriptional control in $\mathrm{CL}-\mathrm{LTP}_{\mathrm{mGluR} 1}$. The activity of CREB in transcription is mediated via phosphorylation of key regulatory site Serine 133, which provides a readout of its activation (Gonzalez and Montminy, 1989). The cL$\mathrm{LTP}_{\text {mGluR1 }}$ induction protocol (repeated mGluR1 stimulation) was applied to acute hippocampal slices from GAD67-GFP knock-in mice (Tamamaki et al., 2003) and pCREB was determined specifically in GFP-labeled OA-INs by immunofluorescence. pCREB was increased in OA-INs at 30 and $60 \mathrm{~min}$ following repeated $\mathrm{mGluR} 1$ stimulation, relative to sham treat- 
A

\section{Day of treatment Next day recording}

Slice culture
preparation

(PN7-9)

DIV

0

B

\section{4 hours post:}
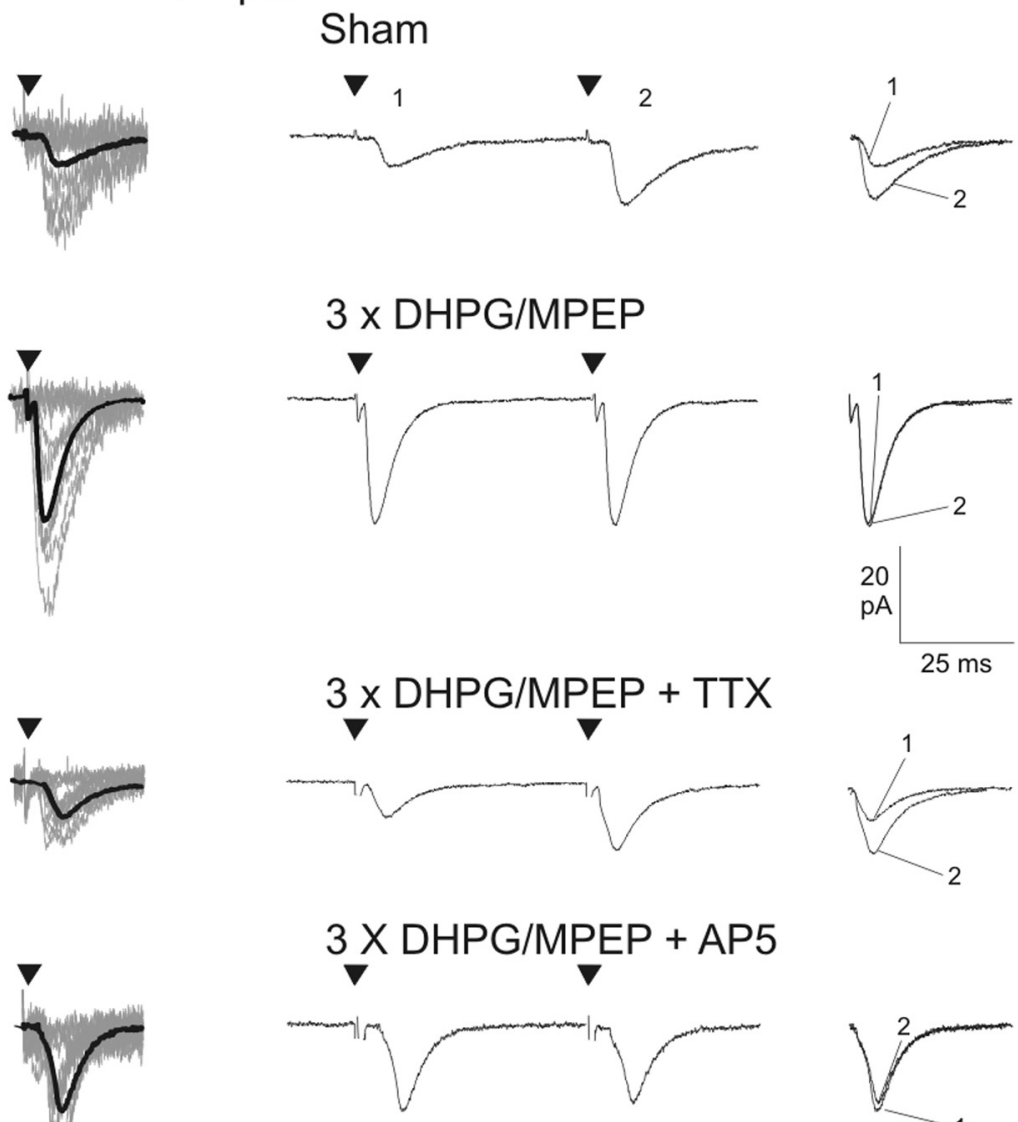

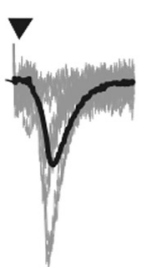

mGluR1/5 agonist(DHPG) | | |

mGluR5 antagonist(MPEP)

With or without TTX or AP5

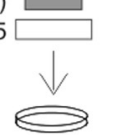

6

$(5-7)$
C

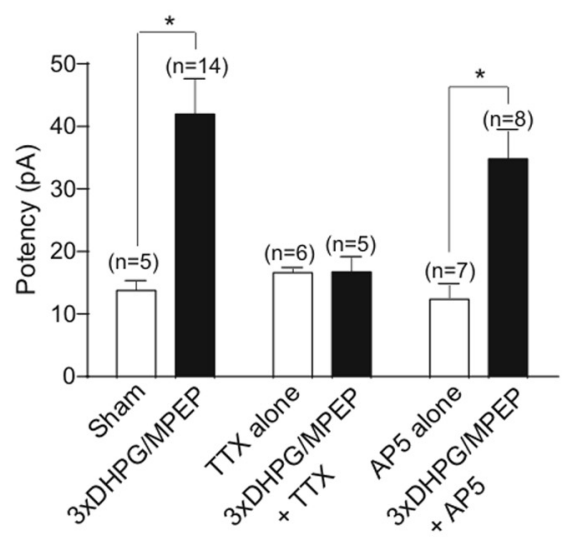

$(6-8)$

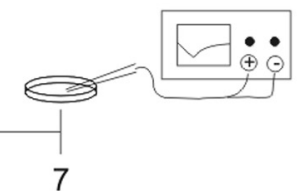


A

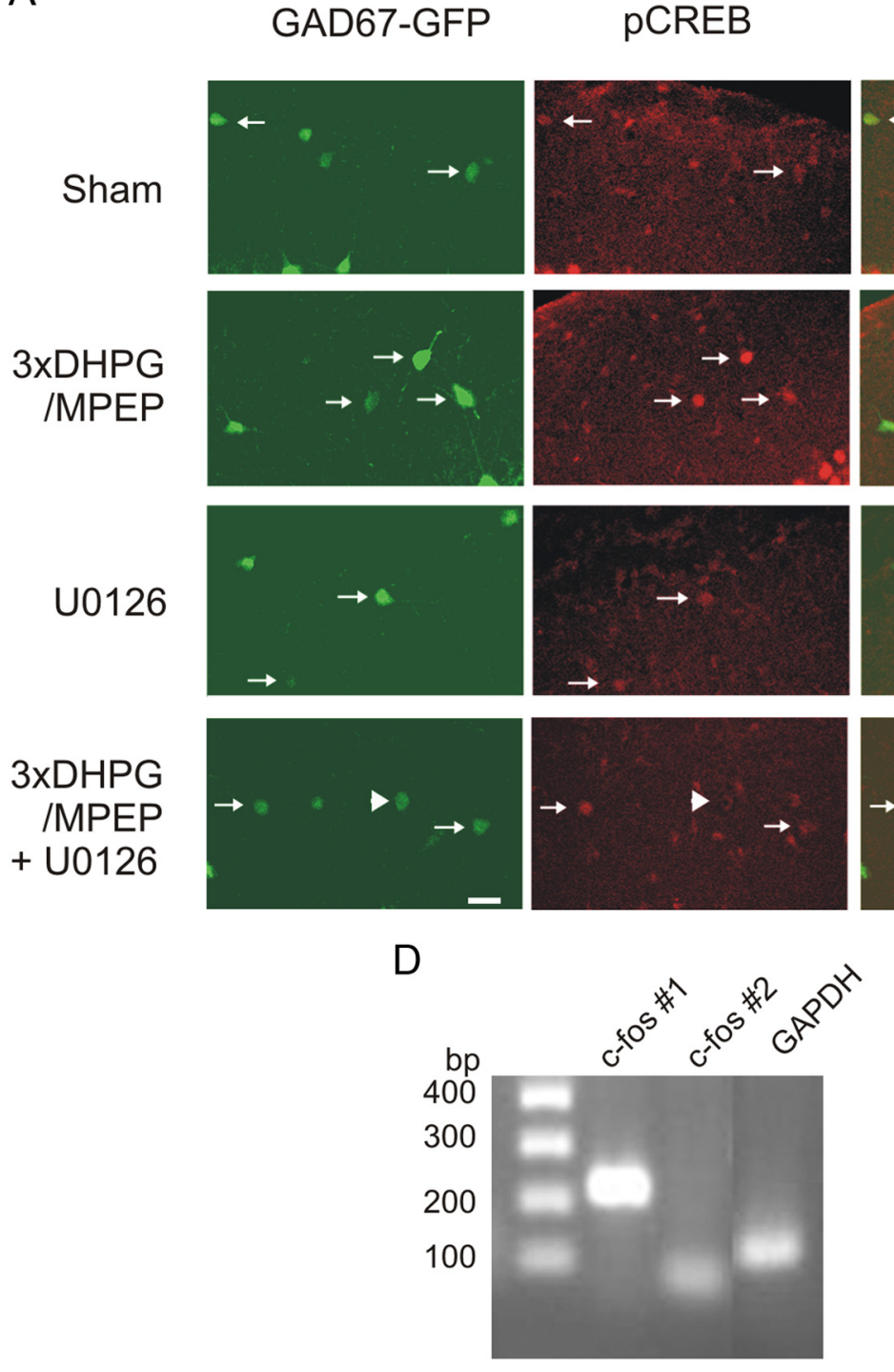

Merged
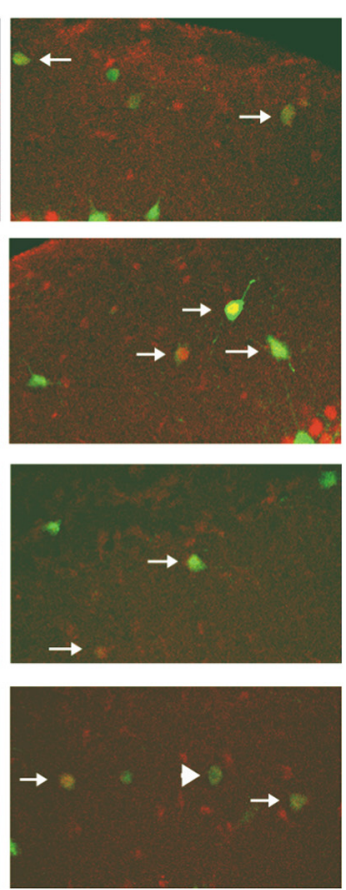

B

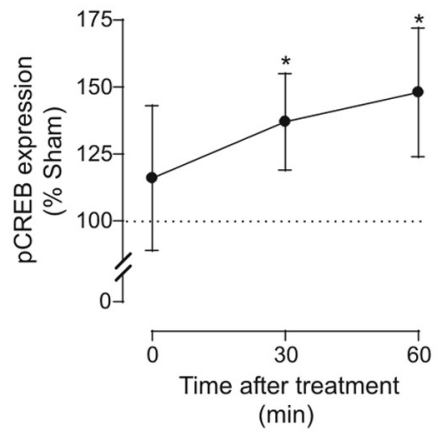

C

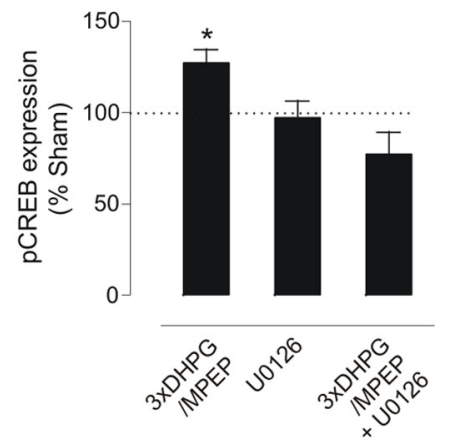

Figure 2. Repeated mGluR1 stimulation increases pCREB in OA-INs. A, Immunofluorescence labeling of pCREB (middle) in GAD67-GFP labeled OA-INs (left) in acute hippocampal slices. Arrows point at $0 A-I N$ s positive for nuclear $p C R E B$ and large arrowheads point at non-nuclear $P C R E B$ in $O A-I N$ excluded from the analysis. pCREB immunolabeling is increased at 30 min after repeated mGluR1 stimulation ( $3 \times$ DHPG/MPEP) relative to sham treatment, which is prevented by the MEK-ERK inhibitor U0126 (20 $\mu \mathrm{M})$. By itself, U0126 had no effect on pCREB level relative to sham. Scale bar, 20 $\mu \mathrm{m} . \boldsymbol{B}$, Time course of increase in CREB phosphorylation at 0,30, and $60 \mathrm{~min}$ following $3 \times$ DHPG/MPEP treatment. Immunofluorescence was quantified as integrated pixel density (see Materials and Methods) and normalized to a sham-treated group at each time point (\% of sham treated). pCREB is significantly increased at 30 min following $3 \times$ DHPG/MPEP treatment. C, Summary bar graph illustrating the increase in pCREB at 30 min following repeated mGluR1 stimulation, which is blocked by U0126. Results are expressed as mean \pm SEM and from 3 independent experiments ( 2 animals; 3 of 6 representative sections from each animal). D, Increased c-fos mRNA expression in OA-INs harvested after repeated mGluR1 stimulation ( $3 \times$ DHPG/MPEP) in slice cultures. Left, Agarose gel electrophoresis of qPCR products for c-fos and GAPDH. Note base pair (bp) ladder on left side. Right, Summary bar graph showing increase in c-fos expression after repeated mGluR1 stimulation, which is blocked by the MEK-ERK inhibitor U0126. Results are from 5 independent experiments, each with 3 pooled cells. Values are expressed as mean \pm SEM; ${ }^{*} p<0.05$ using unpaired $t$-tests $(\boldsymbol{B}, \boldsymbol{D})$ and one-way ANOVA $(\boldsymbol{C})$.

tip diameter). OA-INs were pooled ( $n=3$ cells) for quantitative RT-PCR analysis (Durand et al., 2006) to assess c-fos expression. Repeated mGluR1 stimulation elicited about a $477 \pm 165 \%$ increase in c-fos mRNA expression in OA-INs, relative to sham treatment (Fig. 2D). Consistent with our finding that CREB phosphorylation by repeated mGluR1 stimulation was ERK dependent, the increase in c-fos expression after repeated mGluR1 stimulation was prevented by the MEK-ERK inhibitor U0126 (Fig. $2 D$ ). These data suggest that the $\mathrm{CL}^{-\mathrm{LTP}_{\mathrm{mGluR} 1}}$ induction protocol stimulates CREB phosphorylation via ERK signaling and increases expression of CREB-dependent genes like c-fos in OA-INs.
Since our findings suggest that induction of cL-LTP ${ }_{\text {mGluR1 }}$ activates pCREB and CREB-dependent gene expression in OAINs, we next examined if CREB was necessary for $\mathrm{cL}-\mathrm{LTP}_{\mathrm{mGluR} 1}$ using siRNA. First, we used immunofluorescence to verify that biolistic transfection of siRNA against CREB was effective in reducing CREB expression in hippocampal neurons in slice cultures (Fig. 3). Effectively, CREB expression was downregulated by $33 \pm 6 \%$ in YFP-expressing hippocampal neurons cotransfected with a YFP plasmid and siCREB, compared with YFPexpressing neurons cotransfected with a nontargeting siCtl (Fig. $3 B$ ). Having established the efficacy of CREB siRNA, we next

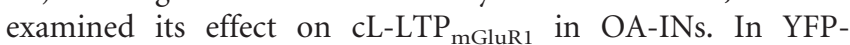


A

Day of transfection

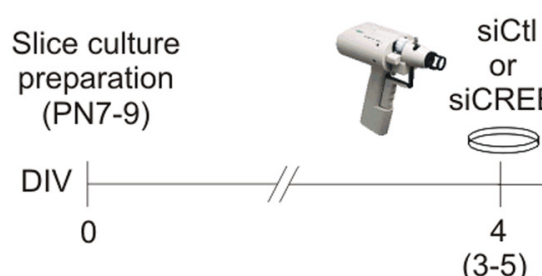

B
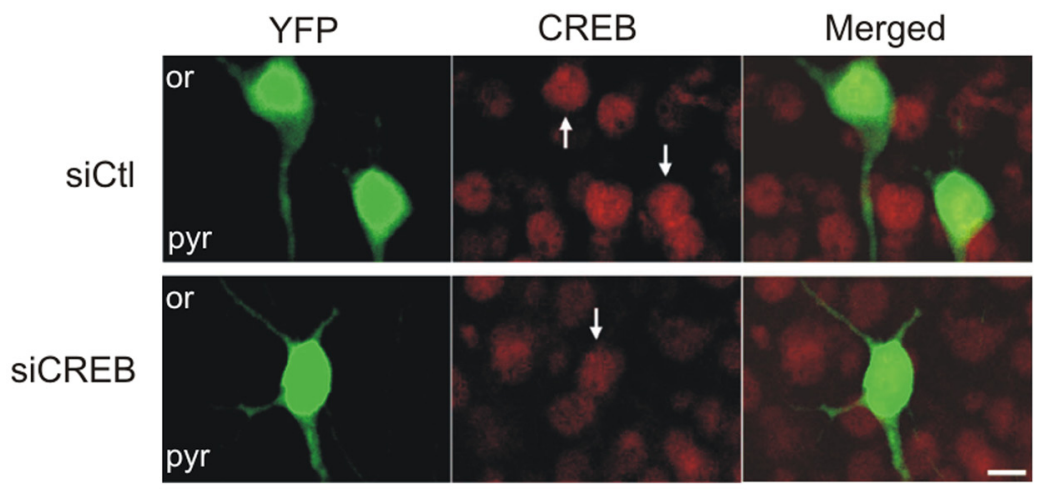

C

\section{siCtl}

\section{4 hours post: Sham}
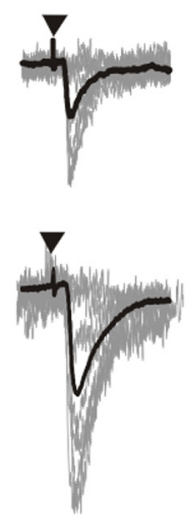

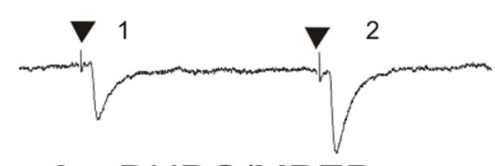

$3 \times$ DHPG/MPEP

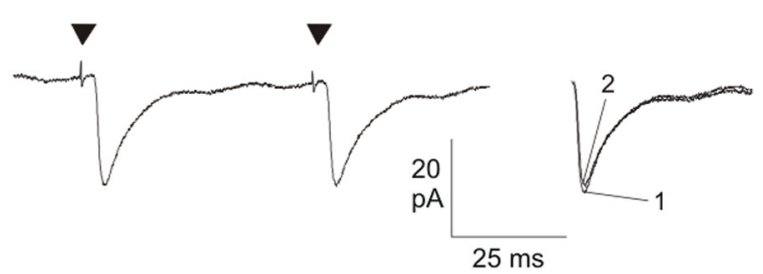

SiCREB
Day of treatment

DHPG I I |

MPEP

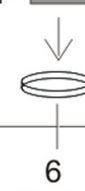

(5-7)
Next day recording

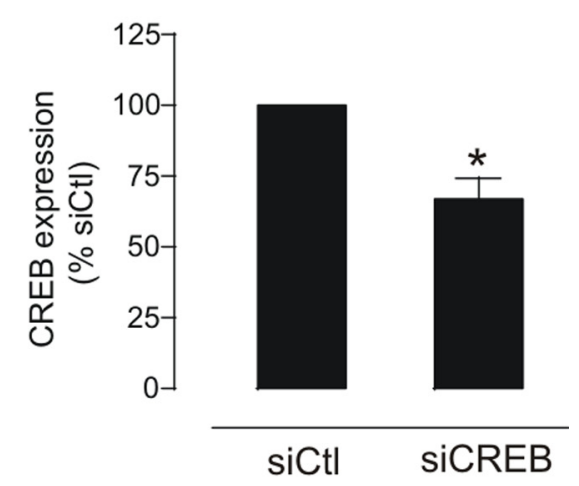

24 hours post: Sham
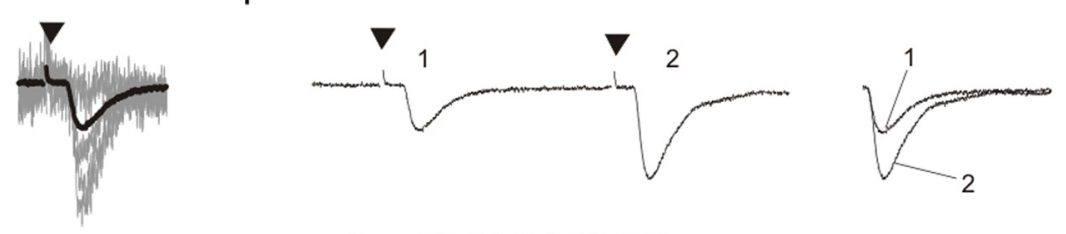

$3 \times$ DHPG/MPEP
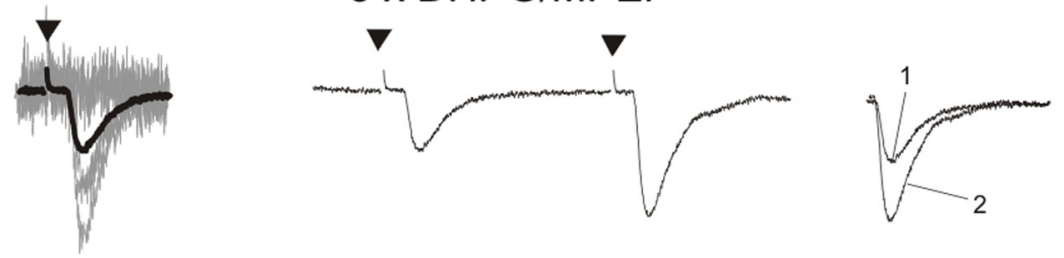

D

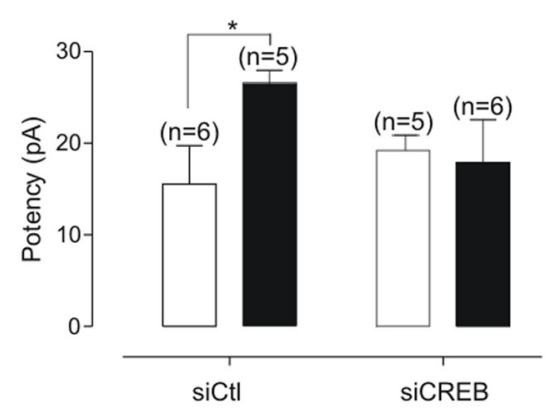

Sham $\square$ 3xDHPG/MPEP

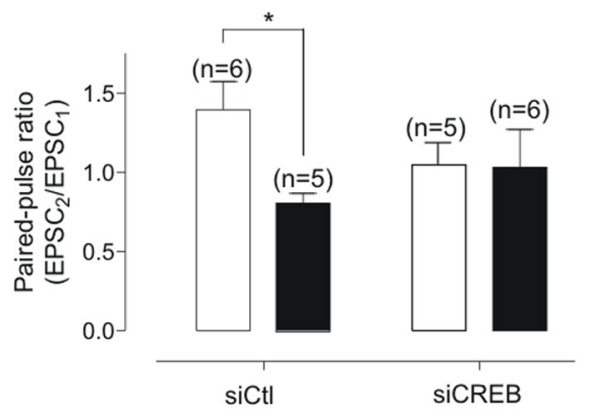

Figure 3. Downregulation of CREB by siRNA prevents $\mathrm{CL}_{\mathrm{LTP}} \mathrm{mGluRT}_{1}$. A, Diagram of transfection, induction, and recording protocol. Cultured hippocampal slices were biolistically cotransfected with a YFP plasmid and siRNA targeting (REB (siCREB) or a control nontargeting siRNA (siCtl). At $48 \mathrm{~h}$ post-transfection, slices received repeated mGluR1 stimulation (3X DHPG/MPEP) (Figure legend continues.) 
expressing OA-INs cotransfected with nontargeting siRNA ( iCtl), repeated mGluR1 stimulation resulted in a $70 \pm 9 \%$ increase in EPSC potency and a $41 \pm 4 \%$ decrease in PPR at $24 \mathrm{~h}$ postinduction relative to sham treatment, indicative of cL$\mathrm{LTP}_{\text {mGluR1 }}$ (Fig. $3 C, D$ ). In contrast, $\mathrm{CL}^{-\mathrm{LTP}_{\text {mGluR1 }}}$ was absent in YFP-expressing OA-INs cotransfected with siCREB (Fig. 3C,D). Thus, a moderate (33\%) downregulation of CREB level by siRNA appears to be sufficient for completely preventing cL-LTP $\mathrm{mGluRl}_{\text {. }}$. Our finding is consistent with previous work showing that a graded (30-40\%) reduction in hippocampal CREB protein levels via infusion of an antisense oligodeoxynucleotide is sufficient to impair consolidation of spatial memory (Guzowski and McGaugh, 1997). Collectively, this series of findings indicates that repeated mGluR1 stimulation activates ERK signaling, leading to CREB phosphorylation and CREB-dependent gene expression, which are necessary steps for the induction of cL-LTP ${ }_{\text {mGluR1 }}$ in OA-INs.

\section{CREB overexpression facilitates cL-LTP mGluR1 $_{\text {induction }}$}

A striking feature of CREB-dependent transcriptional control in long-term synaptic plasticity and memory is that CREB gain-offunction manipulations result in facilitation of the threshold for induction of long-term synaptic plasticity and memory formation (Barco et al., 2002). Therefore, we next determined if upregulation of CREB function by overexpression of GFP-tagged CREB (Han et al., 2007) in OA-INs would selectively affect cLLTP $_{\text {mGluR1 }}$ induction without changing basal synaptic transmission. First we confirmed that GFP-tagged CREB (CREB-GFP) was activated in a similar manner to endogenous CREB (Han et al., 2007) using FSK stimulation in HEK293 cells (Fig. 4). FSK stimulation produced similar increases in phosphorylation of endogenous CREB in cells transfected with CREB-GFP relative to cells transfected with GFP alone ( $58 \pm 15$ vs $50 \pm 17 \%$ increase relative to vehicle [DMSO], respectively) (Fig. 4). Moreover, FSK stimulation also increased phosphorylation of GFP-tagged CREB in the same cells ( $70 \pm 3 \%$ increase relative to vehicle [DMSO]) (Fig. 4), confirming that GFP-tagging of CREB did not interfere with its phosphorylation.

Next we determined the effects of CREB-GFP expression in OA-INs and CL-LTP ${ }_{\text {mGluR } 1}$ induction. Slice cultures were biolistically transfected with CREB-GFP or an empty vector carrying

\footnotetext{
(Figure legend continued.) or sham treatment. After $24 \mathrm{~h}$ recovery, whole-cell recordings were obtained from YFP-expressing OA-INs. B, Left, Immunofluorescence images showing reduced CREB level in YFP-expressing neurons cotransfected with siRNA targeting CREB (siCREB), relative to neurons transfected with a nontargeting siRNA (siCtI). Arrows point to CREB immunolabeling in YFP-expressing CA1 neurons in stratum pyramidale, likely pyramidal cells. Right, Summary bar graph showing reduction of CREB expression (\% of siCt) in neurons transfected with CREB siRNA. Data represent 4 independent experiments, each with at least 15 cells (including OA-INs and pyramidal cells). Or, oriens; pyr, pyramidale. Scale bar, $10 \mu$ m. C, Representative EPSCs evoked by minimal stimulation in YFP-expressing OA-INs transfected with a control nontargeting siRNA (siCtl; top) or CREB siRNA (siCREB; bottom) at $24 \mathrm{~h}$ following sham treatment or repetitive mGluR1 stimulation. Left, Superimposed 20 successive events (EPSCs + failures; gray traces) and average EPSC (including failures; black traces) of 100 events. EPSCs were potentiated after repeated mGluR1 stimulation, relative to sham, in $0 \mathrm{~A}-\mathrm{INs}$ transfected with siCtl, but not in OA-INs transfected with siCREB. Middle, Average of EPSC pairs (100 events) evoked by paired-pulse stimulation (50 ms interstimulus interval), showing reduction of paired-pulse facilitation after repeated mGluR1 stimulation in 0A-INs transfected with siCtl but with siCREB. Right, Superimposed first and second EPSCS of average pair. Black triangles indicate time of stimulation. $D$, Summary bar graphs of effects on EPSC potency and PPR for all YFP-expressing OA-INs, showing potentiation of EPSC potency and reduced PPR $24 \mathrm{~h}$ after repeated mGluR1 stimulation, relative to sham treatment, in cells transfected with siCtl but not siCREB. Values are expressed as mean \pm SEM; ${ }^{*} p<0.05$ using one-sample $(\boldsymbol{B})$ and unpaired $(\boldsymbol{D}) t$ test. Number of cells are indicated above bar.
}

A

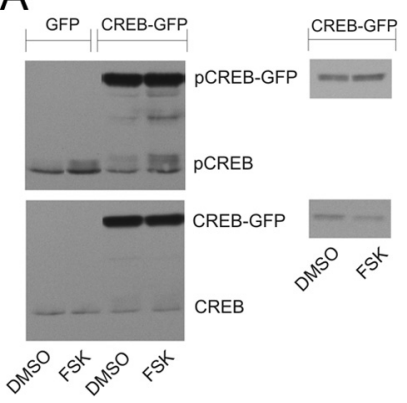

B

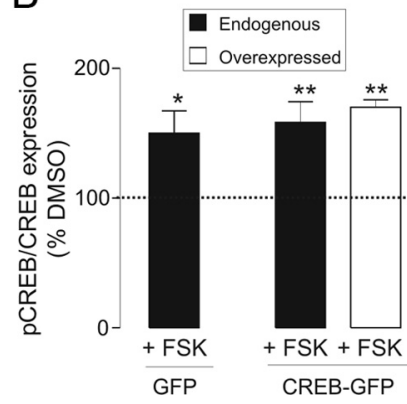

Figure 4. CREB-GFP tagging does not interfere with $p C R E B$. $A$, Representative immunoblots from HEK293 cells transfected with vectors for GFP alone (GFP) or GFP-tagged CREB (CREB-GFP) following a 15 min treatment with $50 \mu \mathrm{M}$ FSK or vehicle alone (DMSO). Immunoblots were incubated with antibodies specific for pCREB (top) or total CREB (bottom). FSK-induced phosphorylation of both endogenous (pCREB/CREB) and overexpressed (pCREB-GFP/CREB-GFP higher molecular weight with GFP-tag) proteins. Right, Bands obtained at shorter film exposure. $\boldsymbol{B}$, Bar graphs summarizing densitometric analysis of $p$ CREB/CREB expression. Data from FSK-treated cells are expressed as a percentage of values obtained from DMSO-treated contro group for each transfected condition. Values are presented for endogenous pCREB/CREB (black) and overexpressed pCREB-GFP/CREB-GFP (white) ratios. Dotted line equals DMSO control group. Results are expressed as mean \pm SEM and represent at least 3 independent experiments done in duplicates; one $\left(^{*}\right)$ - or two $\left(^{* *}\right)$-tailed $t$-tests were used to compare differences between FSK and DMSO control groups, $p<0.05$.

GFP alone, followed by sham treatment, single, or repeated mGluR1 stimulation at $48 \mathrm{~h}$ posttransfection. Whole-cell recordings were obtained $24 \mathrm{~h}$ later from GFP-expressing transfected and untransfected OA-INs in the same slice (Fig. 5). In shamtreated slices, transfection of CREB-GFP had no effect on basal synaptic transmission relative to untransfected cells (Fig. 5A). The potency and PPR values of EPSCs evoked by minimal stimulation did not differ in pairs of CREB-GFP-transfected and untransfected OA-INs after sham treatment (Fig. 5B). EPSC potency and PPR values in plots of transfected versus untransfected OA-IN pairs after sham treatment fall close to the unity line (Fig. 5C). Cell input resistance was also unaffected (214 \pm 63 $\mathrm{M} \Omega$ in CREB-GFP transfected versus $210 \pm 33 \mathrm{M} \Omega$ in untransfected cells, $p>0.05, t$ test). In contrast, a single mGluR1 stimulation, which is subthreshold for $\mathrm{cL}^{-L T P} \mathrm{~m}_{\mathrm{m} \text { luR1 }}$ induction in untransfected cells, was sufficient to elicit cL-LTP ${ }_{\text {mGluR } 1}$ in CREB-GFP-transfected OA-INs (Fig. 5A). EPSC potency was increased by $132 \pm 28 \%$ while PPR was decreased by $34 \pm 2 \%$ after single mGluR1 stimulation, relative to sham treatment, in CREB-GFP-transfected OA-INs (Fig. 5B). EPSCs were unchanged after single mGluR1 stimulation, relative to sham treatment, in untransfected OA-INs. Thus, overexpression of CREB is not sufficient to induce a potentiation of basal excitatory transmission, but results in a facilitation of the threshold for induction of cL-LTP mGluR1 $_{\text {. }}$.

Interestingly, repeated mGluR1 stimulation similarly induced cL-LTP $_{\text {mGluR } 1}$ in CREB-GFP-transfected and untransfected OAINs, relative to sham treatment (potency increase of $140 \pm 53 \%$ in transfected and $84 \pm 16 \%$ in untransfected cells; PPR decrease of $40 \pm 3 \%$ in transfected and $38 \pm 3 \%$ in untransfected cells) (Fig. 5). EPSC potency and PPR values in plots of transfected versus untransfected OA-IN pairs after repeated mGluR1 stimulation fall close to the unity line (Fig. 5C). In control experiments with transfection of empty vector and GFP, EPSC potency and PPR were unchanged after single mGluR1 stimulation, relative to sham treatment, in GFPtransfected or untransfected OA-INs (Fig. 5D), indicating that facilitation of the threshold for cL-LTP ${ }_{\text {mGluR } 1}$ induction was a selective 
A Untransfected

24 h post: Sham
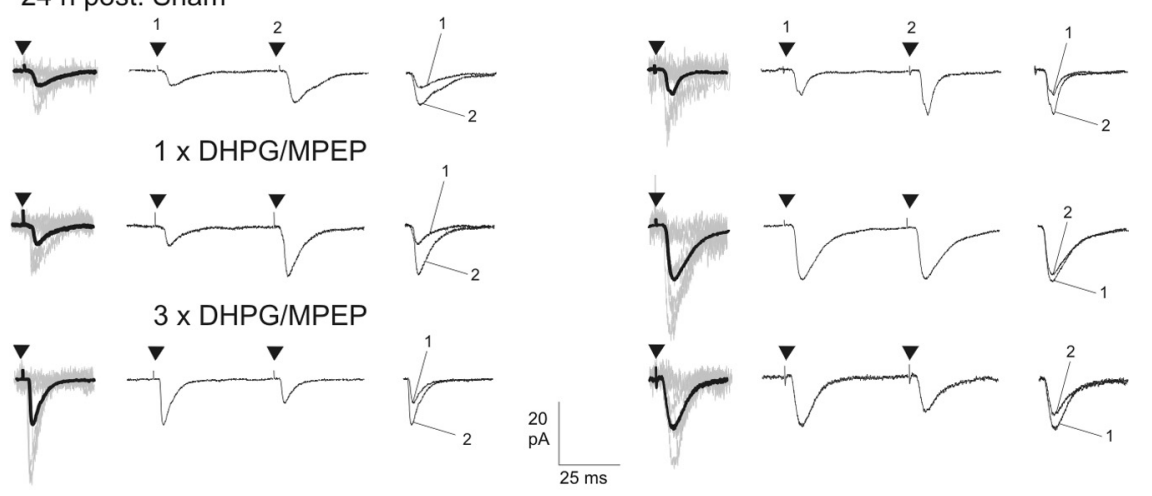

B
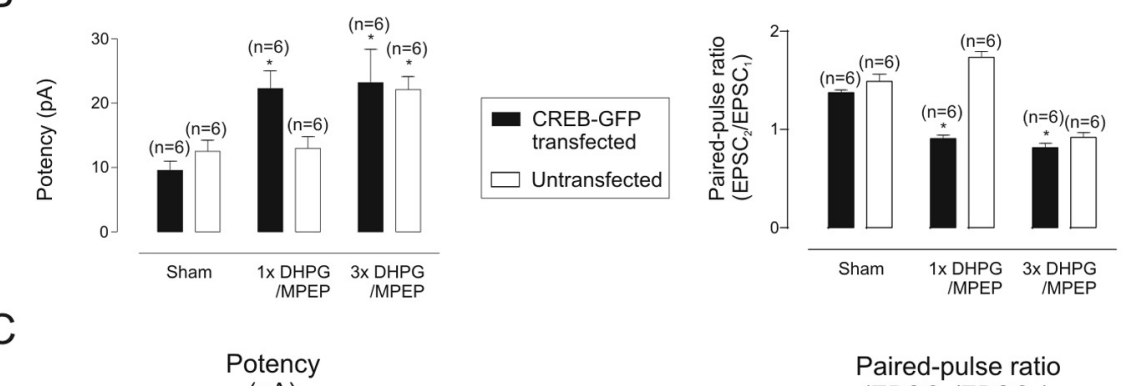

$(\mathrm{pA})$
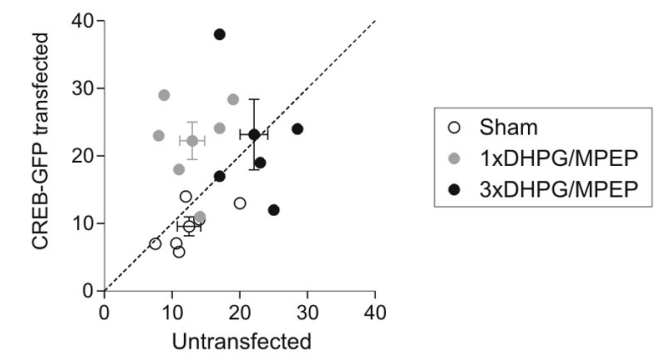

D
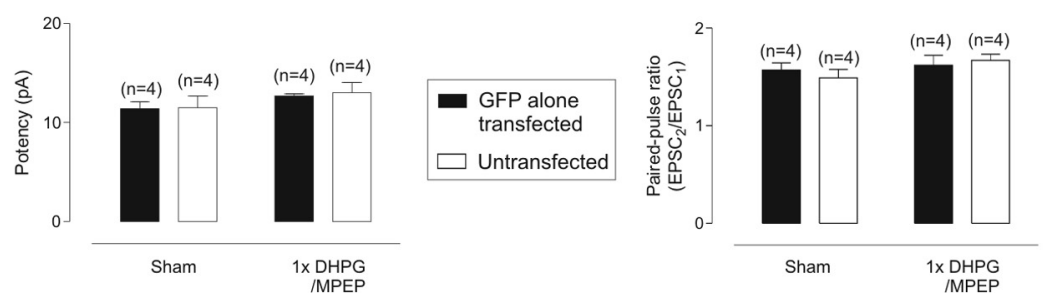

Figure 5. Expression of CREB facilitates CL-LTP $\mathrm{mGluR}_{1}$ induction. $\boldsymbol{A}$, Representative EPSCs evoked by minimal stimulation at $24 \mathrm{~h}$ following sham treatment (top), single (middle) or repeated (bottom) mGluR1 stimulation in CREB-GFP transfected (right), or untransfected (left) OA-INs in the same slice. Left, Superimposed 20 successive events (EPSCS + failures; gray) with average EPSC (including failures; black) from 100 events. Middle, Average of EPSC pairs (100 events) evoked by paired-pulse stimulation ( $50 \mathrm{~ms}$ interstimulus interval). Right, Superimposed first and second EPSCs of average pair. Black triangles indicate time of stimulation. EPSC amplitude and paired-pulse facilitation are similar in untransfected and transfected cells after sham treatment. EPSCs are potentiated and paired-pulse facilitation reduced after single mGluR1 stimulation, relative to sham treatment, in CREB-GFPtransfected OA-INs, but not in untransfected cells. B, Summary bar graphs of EPSC potency and PPR for CREB-GFP experiments, showing increased EPSC potency and reduced PPR after single mGluR1 stimulation, relative to sham treated, selectively in CREBGFP-transfected cells. EPSC potentiation and reduced PPR are observed in untransfected OA-INs only after repeated mGluR1 stimulation. C, Scatter plots of EPSC potency and PPR values for CREB-GFP-transfected versus untransfected OA-INs. Diagonal line indicates unity. Data points deviate substantially from unity only for the single $\mathrm{mGluR1}$ stimulation group, indicating a facilitation of the threshold for induction in CREB-GFP-transfected cells. D, Summary bar graphs of EPSC potency and PPR for GFP control experiments showing no difference in potency and PPR after single mGluR1 stimulation, relative to sham treated, in GFPtransfected control cells or untransfected cells. Values are expressed as mean $\pm \mathrm{SEM} ;{ }^{*} p<0.05$ using $t$ test $(\boldsymbol{D})$ or two-way ANOVA $(\boldsymbol{B})$. Number of cells are indicated above bar. effect of CREB overexpression and not due to nonspecific effects of transfection. Thus, CREB overexpression does not increase the level of $\mathrm{cL}-\mathrm{LTP}_{\mathrm{mGluR} 1}$; it regulates the threshold for induction. Altogether, these results indicate that CREBdependent transcriptional control is not sufficient but permissive for cLLTP $_{\text {mGluR1 }}$ in OA-INs and regulates its induction threshold.

\section{Quantal changes in cL-LTP ${ }_{\text {mGluR1 }}$ expression}

Next we addressed the mechanisms underlying the maintenance of cL-LTP ${ }_{\text {mGluR1 }}$. Previous findings suggest that both presynaptic and postsynaptic changes contribute to $\mathrm{CL}^{-\mathrm{LTP}_{\mathrm{mGluR} 1}}$ expression (Ran et al., 2009). Decreases in EPSC PPR and increases in mEPSC frequency are consistent with presynaptic changes, whereas the increases in EPSC potency and mEPSC amplitude are compatible with postsynaptic changes (Ran et al., 2009). To explore the presynaptic and postsynaptic mechanisms underlying these persistent changes in synaptic efficacy, we performed quantal analysis of unitary synaptic transmission at OA-IN synapses dur-

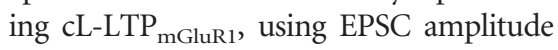
histogram analysis and fitting of multiple Gaussian functions (Bolshakov et al., 1997). The analysis was performed on subsets of data obtained previously (Ran et al., 2009) that showed EPSCs evoked by minimal stimulation with stationary recording conditions for the 20-30 min acquisition period (see Materials and Methods). In sham-treated slices, the amplitude histogram of EPSCs evoked by minimal stimulation displayed in most cells two identifiable peaks well fitted with a sum of two Gaussian functions (Fig. $6 A)$. The left peak centered at zero represents EPSC failures and its Gaussian function is noise. The first peak to the right corresponds to EPSC successes and its Gaussian function reflects the release of a single quantum of transmitter in response to stimulation.

In slices that received repeated mGluR1 stimulation, the EPSC potency and coefficient of variation were increased, respectively, by $150 \pm 11$ and $40 \pm 3 \%$ relative to sham-treated slices (Fig. 6B). The EPSC amplitude histogram distribution was broadened and best fitted by a sum of multiple Gaussian functions (Fig. 6A,C). The amplitude peaks of the multiple Gaussian functions for EPSC successes were $>2$ in all cells (range $2-4$; Fig. $6 C$ ), suggesting the release of two or more quanta of transmitter in response to stimulation. The multiple peaks also appeared approximately equidistant, which, according to classical quantal analysis (Del 
A

$24 \mathrm{~h}$ post:

Sham

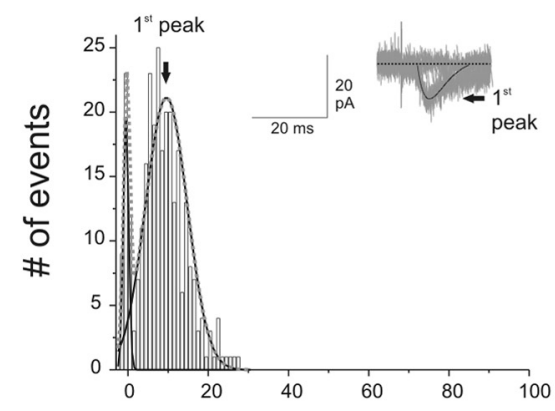

B

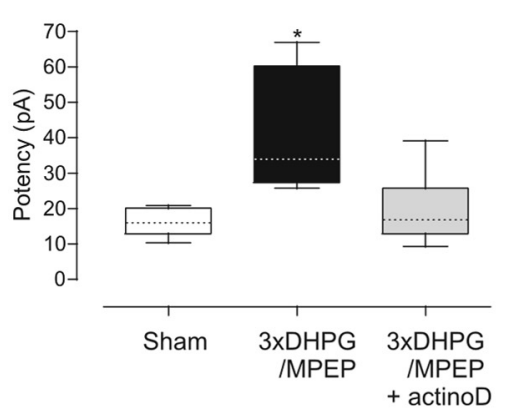

$3 \times$ DHPG/MPEP

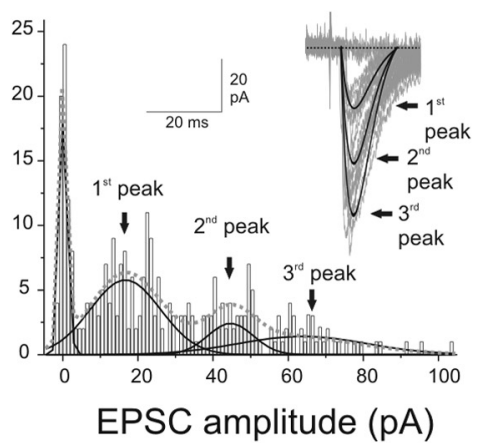

$3 \times$ DHPG/MPEP + actinoD
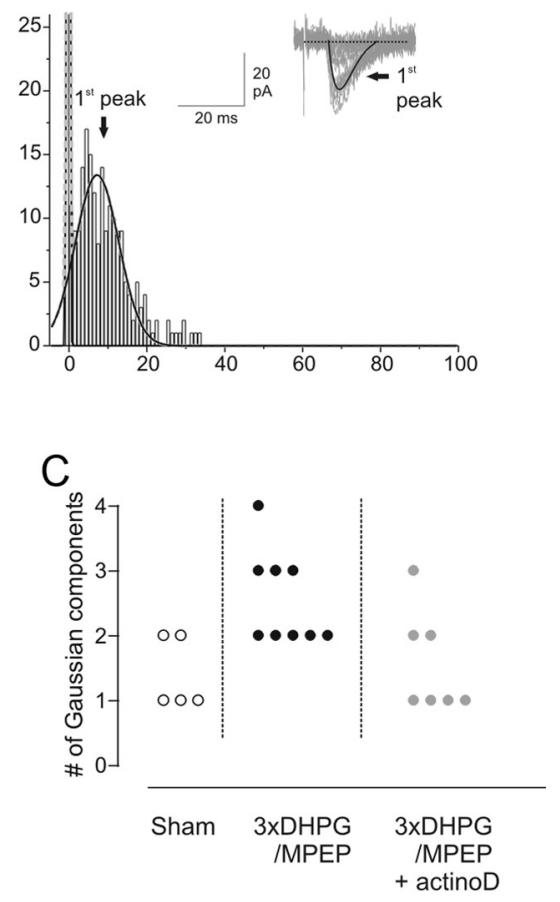

D
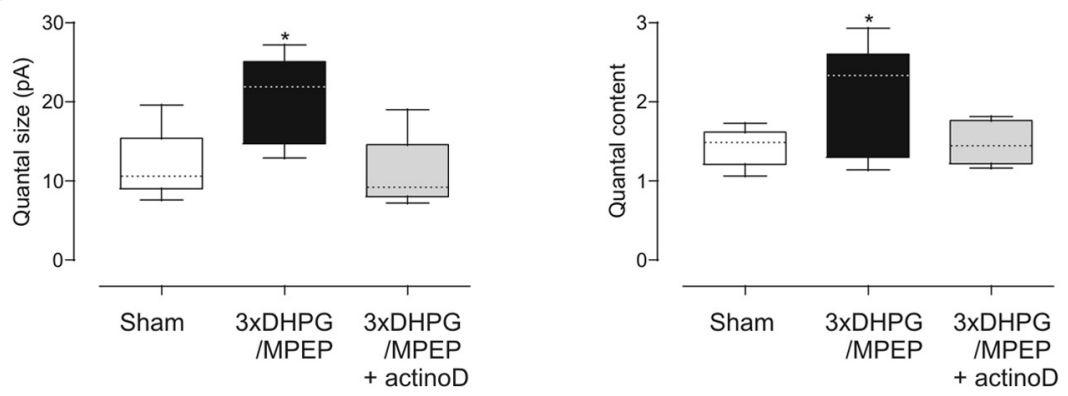

Figure 6. EPSC amplitude histogram analysis reveals quantal changes during CL-LTP ${ }_{m G l u R 1} \cdot A$, Example of amplitude histograms of EPSCs evoked by minimal stimulation in $0 A-I N s$ from slices receiving sham treatment (left), repeated mGluR1 stimulation ( $3 \times$ DHGP/MPEP; middle), or repeated mGluR1 stimulation in presence of the transcription inhibitor actinomycin D $(3 \times$ DHGP/MPEP + actinoD; right). Vertical arrows (black) point at peaks of Gaussian functions of EPSC successes. Insets, Overlapping traces of EPSC successes and failures (40 traces in gray; black trace corresponds to an $\alpha$ function-fit scaled to the center of the Gaussian). The EPSC amplitude histograms were different after repeated mGluR1 stimulation with a broader distribution, fit by multiple Gaussian functions, and a larger peak of the first Gaussian function. B, Summary box plots showing the increase in EPS ( potency (successes only) and coefficient of variation after repeated mGluR1 stimulation. Data are from sham $(n=5), 3 \times$ DHPG/MPEP $(n=9)$ and $3 \times$ DHPG/MPEP + actinoD $(n=7)$-treated slices. C, Summary plot showing the increase in the number of Gaussian functions fitted to the EPSC amplitude histograms after repeated mGluR1 stimulation. $\boldsymbol{D}$, Summary box plots illustrating the increase in quantal size (peak of first Gaussian function) and quantal content (potency/ quantal size) after repeated mGluR1 stimulation. $\boldsymbol{B}, \boldsymbol{D},{ }^{*} p<0.05$ using one-way ANOVA.

Castillo and Katz, 1954; Redman, 1990), represents the simultaneous release of an increasing number of quanta. Thus, during cL-LTP mGluR $1_{1}$ the increase in EPSC amplitude is due in part to an increase in the number of quanta released (i.e., increase in quantal content).

The Gaussian function of the first peak of EPSC successes was also changed in slices that received repeated mGluR1 stimulation. The peak of the Gaussian function was larger and shifted to the right, relative to sham-treated slices (72 $\pm 1 \%$ increase) (Fig. $6 A, D$ ), which according to classical quantal analysis (Del Castillo and Katz, 1954; Redman, 1990) reflects a twofold increase in the postsynaptic response to a single quantum of transmitter. Thus, the increase in EPSC amplitude during cL-LTP mGluR $_{1}$ is also due in part to an increase in quantal size (i.e., quantal amplitude).
Consistent with the peak amplitude histogram analysis, the estimate of quantal content obtained by dividing the mean amplitude of successful EPSCs (potency) by quantal size was increased by $42 \pm$ $5 \%$ in slices that received repeated mGluR1 stimulation relative to sham treatment (Fig. 6D). Moreover, concomitant application of the transcription inhibitor actinomycin $\mathrm{D}(40 \mu \mathrm{M})$ during repeated mGluR1 stimulation blocked CL-LTP ${ }_{\text {mGluR1 }}$ induction and prevented the increases in EPSC potency and coefficient of variation, as well as the increases in quantal content and quantal size (Fig. 6A-D). Overall these results suggest that the expression mechanisms during transcription-dependent cL-LTP ${ }_{\text {mGluR1 }}$ involve a presynaptic increase in the number of quanta released (increase in quantal content) and a postsynaptic increase in the response to a single quantum of transmitter released (increase in quantal size). 


\section{Changes in glutamate receptor properties and number in cL-LTP $_{\text {mGluR1 }}$ expression}

Given that cL-LTP ${ }_{\text {mGluR1 }}$ is expressed in part as an increase in quantal size which according to classical quantal analysis (Del Castillo and Katz, 1954; Redman, 1990) reflects a change in the postsynaptic response to a single quantum of transmitter, we next examined the postsynaptic mechanisms involved. We used nonstationary fluctuation analysis to estimate changes during cLLTP $_{\text {mGluR1 }}$ in single-channel conductance and/or number of receptors contributing to $\mathrm{mEPSC}$ activated by a single transmitter quantum (Hartveit and Veruki, 2007). Moreover, peak-scaled nonstationary noise analysis was employed to compensate for quantal variability (both quantal size and number of quanta) in miniature synaptic currents in OA-INs (Hartveit and Veruki, 2007). The fluctuation analysis was performed on subsets of data obtained previously (Ran et al., 2009) that showed mEPSCs with stationary recording conditions throughout the 20-30 min acquisition period (see Materials and Methods).

From the ensemble of mEPSCs in each cell (Fig. 7A), the mean mEPSC waveform was scaled to the peak amplitude of each mEPSC waveform and then the variance of current fluctuations about the mean were calculated for each point in time (Fig. $6 \mathrm{~B}$; Hartveit and Veruki, 2007). From the parabolic relation between the variance and mean mEPSC (Fig. 7C), we obtained estimates of single-channel conductance $(\gamma)$ and the average number of channels opened at the peak of the response $(N)$ for mEPSCs in OA-INs recorded $24 \mathrm{~h}$ after sham treatment or repeated mGluR1 stimulation (Fig. $7 C, D$ ). Both single-channel conductance $(\gamma)$ and the average number of channels opened at the peak response $(N)$ were increased by $99 \pm 6$ and $60 \pm 3 \%$, respectively, in OA-INs after repeated mGluR1 stimulation relative to sham treatment (Fig. 7D). Hence, the nonstationary fluctuation analysis indicates that an increase in both single-channel conductance and number of receptors contributing to mEPSCs underlies the increase in the postsynaptic response to a single quantum of transmitter during cL-LTP ${ }_{\text {mGluR } 1}$ expression.

\section{Intact rectification and NMDA/non-NMDA receptor ratio during cL-LTP ${ }_{\text {mGluR1 }}$}

We next examined if the alteration in single-channel conductance observed in $\mathrm{CL}^{-\mathrm{LTP}_{\mathrm{mGluR} 1}}$ may reflect a change in glutamate receptor subunits at the synapse (Liu and Cull-Candy, 2000) by determining if inward rectification of EPSCs was altered

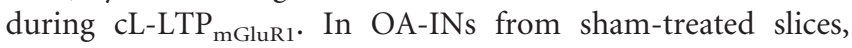
EPSCs (evoked at $2 \times$ threshold stimulation intensity) showed inward rectification (Fig. $8 \mathrm{~A}$ ), consistent with previous evidence that synaptic inputs to OA-INs are composed of $\mathrm{Ca}^{2+}$-permeable non-NMDA receptors (Croce et al., 2010). Moreover, at $24 \mathrm{~h}$ after repeated mGluR1 stimulation, EPSCs showed similar inward rectification and the rectification index was not different relative to sham treatment (Fig. $8 \mathrm{~B}$ ). To further assess changes in subunit composition, we examined if the sensitivity of nonNMDA EPSCs to the $\mathrm{Ca}^{2+}$-permeable AMPA receptor blocker IEM-1460 was altered during CL-LTP mGluR1 $_{1}$. EPSCs were blocked to the same extent by IEM-1460 at $24 \mathrm{~h}$ following sham treatment (59 $\pm 4 \%$ reduction) and repeated mGluR1 stimulation $(56 \pm 6 \%$ reduction) (Fig. $8 C, D$ ), consistent with the unaltered rectification and suggesting that $\mathrm{CL}-\mathrm{LTP}_{\mathrm{mGluR} 1}$ does not alter the proportion of $\mathrm{Ca}^{2+}$-permeable AMPA receptors expressed in OA-INs. Thus, the glutamate receptor subunit composition at OA-IN synapses appears unchanged during cL-LTP ${ }_{\text {mGluR1 }}$.

Finally, we examined if the changes in quantal size during $\mathrm{cL}_{-} \mathrm{LTP}_{\text {mGluR } 1}$ may involve the selective recruitment of functional

A 24 h post:

Sham

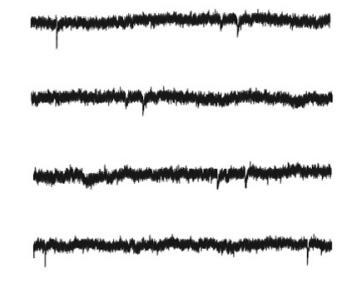

B

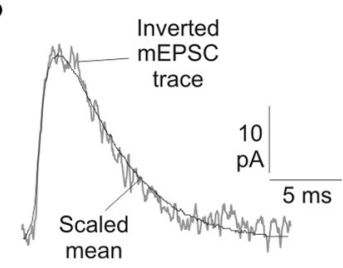

$\mathrm{C}_{24}$
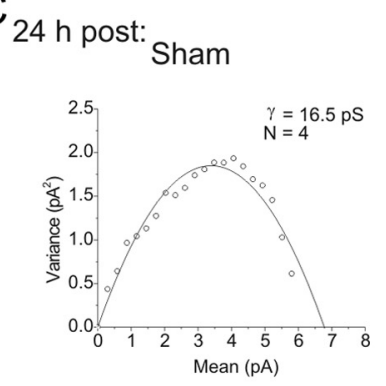

D
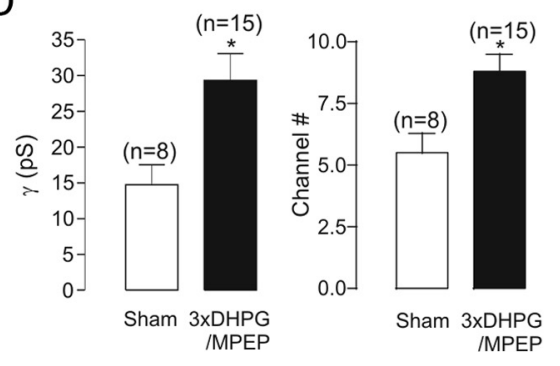

Figure 7. Peak-scaled nonstationary fluctuation analysis reveals changes in channel properties and number of receptors during $\mathrm{CL}^{-L T P} \mathrm{PGluR}_{\mathrm{m} 1} \cdot A$, Representative recordings of $\mathrm{mEPSC}$ (in $1 \mu \mathrm{M}$ TTX) showing more frequent and larger events in cells that received repeated mGluR1 stimulation (right), relative to sham treatment (left). $\boldsymbol{B}$, Left, Representative example from another OA-IN after sham treatment showing a single mEPSC waveform (gray) and the mean mEPSC (275 events, black) scaled to the individual mEPSC peak. Right, Corresponding variance of difference currents (gray; individual mEPSCs-mean mEPSC). Dotted line corresponds to the mean mEPSC. Arrows indicated the region used for fluctuation analysis. $\boldsymbol{C}$, Representative examples of variance-mean plots for the ensembles of mEPSCs fitted with a parabola from individual OA-INs after sham treatment (left; same cell as in $\boldsymbol{B}$ ) and repeated mGluR1 stimulation (right). Note the increase in mean mEPSC amplitude after repeated mGluR1 stimulation. For comparison, the parabola function from the sham-treated cell is illustrated (sham) in the plot of the cell with repeated mGluR1 stimulation. $D$, Summary bar graphs for all cells ( $n=8$ in sham and $n=15$ in repeated mGluR1 stimulation groups) showing increases in single-channel conductance ( $\gamma$; left) and average number of channels opened at the peak of the response $(N$; right) after repeated mGluR1 stimulation (filled bars) relative to sham-treatment (open bars). Values in $\boldsymbol{D}$ are expressed as mean \pm SEM; ${ }^{*} p<0.05$ using $t$ test. Number of cells are indicated above bars.

non-NMDA receptors at synapses (Shi et al., 1999) by investigating the relative contributions of NMDA and non-NMDA receptors to EPSCs. The ratio of the amplitude of NMDA and non-NMDA receptor components of EPSCs (NMDA/non-NMDA ratio) was not altered at $24 \mathrm{~h}$ after repeated mGluR1 stimulation compared with 
sham treatment (Fig. $8 E, F)$. Hence, the increase in postsynaptic responsiveness during cL-LTP $_{\text {mGluR1 }}$ does not involve the selective recruitment of functional nonNMDA receptors.

\section{Discussion}

Our results uncover a necessary and permissive role of CREB in transcriptional control during persistent synaptic plasticity that regulates coordinated presynaptic and postsynaptic changes in efficacy at interneuron input synapses (Fig. 9) and may contribute to network changes during hippocampaldependent memory processes.

\section{CREB-dependent}

transcriptional control

The CREB-mediated transcriptional control mechanisms via ERK signaling during cL-LTP ${ }_{\text {mGluR } 1}$ are similar to those in longterm synaptic plasticity in pyramidal cells and other systems (Tully et al., 2003; Lee and Silva, 2009). As for translational control mechanisms (Ran et al., 2009), the mechanisms of transcriptional control in long-term synaptic plasticity appear conserved across hippocampal cell types. Consequently, pharmacological intervention targeting CREB to enhance memory (Tully et al., 2003) may also affect interneurons and result in complex network effects.

CREB overexpression did not affect basal transmission or CL-LTP ${ }_{\text {mGluR1 }}$ elicited by repeated mGluR1 stimulation, but it lowered cL-LTP ${ }_{\text {mGluRl }}$ induction threshold. The unaffected basal transmission suggests that CREB transcription is not sufficient to induce plasticity. The facilitation of induction indicates that CREBmediated transcription is permissive for interneuron persistent plasticity. This permissive role is consistent with the "CREB signature" function acting as a molecular switch for enhancement of long-term synaptic plasticity and memory (Tully et al., 2003). In amygdala networks, specific sets of neurons are recruited during a given auditory fear memory as a function of their CREB activity during learning (Han et al., 2007). ERK activation occurs in CA1 interneurons during contextual learning (Cui et al., 2008), thus monitoring CREB activation following training may help identify interneurons undergoing persistent synaptic plasticity and participating in memory formation during contextual learning.

The increased expression of c-fos after cL-LTP ${ }_{\text {mGluR1 }}$ induction suggests that CREB-dependent genes may be critical for interneuron synaptic plasticity. Brain-derived neurotrophic factor (BDNF) is a CREB-dependent gene implicated in pyramidal cell long-term plasticity (Barco et al., 2005). Activity-dependent BDNF transcription via CREB is implicated in cortical inhibition development (Hong et al., 2008). BDNF and CREB-dependent transcription regulate the development and function of pyrami-
B

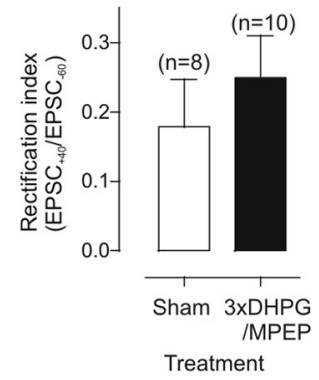

$\mathrm{D}$
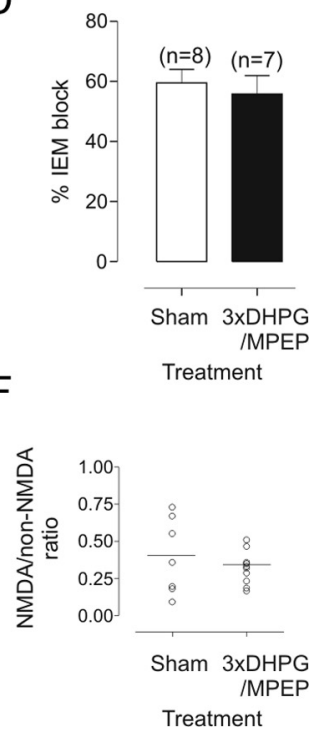

Treatment

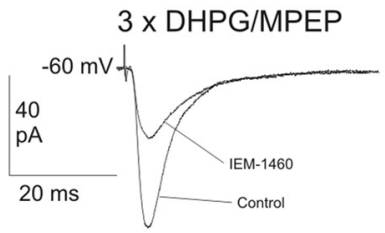

F

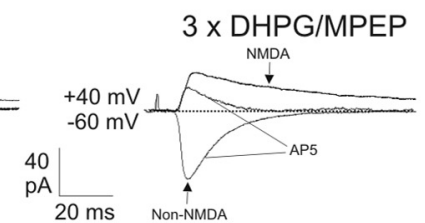

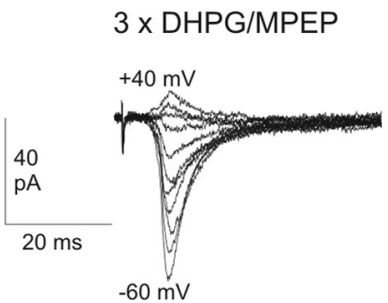

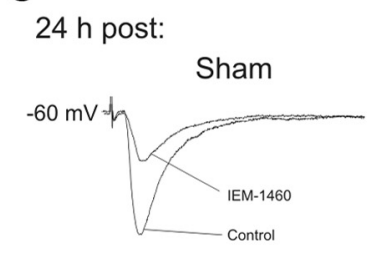

Figure 8. No change in rectification, sensitivity to IEM-1460 and NMDA/non-NMDA ratio of EPSCs during CL-LTP ${ }_{\mathrm{mGluR} 1}$. $\boldsymbol{A}_{\text {, }}$ Representative non-NMDA receptor-mediated EPSCS (stimulation intensity, $2 \times$ threshold) recorded in ACSF containing the NMDA recep-

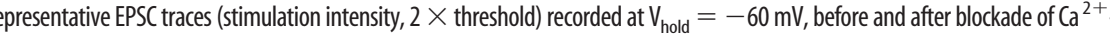

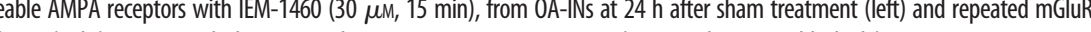
sentative EPSC traces (stimulation intensity, $2 \times$ threshold) recorded at $V_{\text {hold }}=+40 \mathrm{mV}$ and $-60 \mathrm{mV}$, before and after blockade of NMDA receptors with $A P-5$, from $0 A-I N s$ at $24 \mathrm{~h}$ after sham treatment (left) and repeated $\mathrm{mGluR} 1$ stimulation (right). Arrows point at the

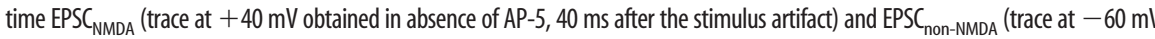
obtained in AP-5) were measured. $\boldsymbol{F}$, Scatter plot showing no change in NMDA to non-NMDA ratio in OA-INs at $24 \mathrm{~h}$ after repeated $\mathrm{mGluR}$ stimulation relative to sham treatment. Data are from the same neurons as in $\boldsymbol{B}$. Values in bar graphs are expressed as mean $\pm S E M ; t$ test was used for comparisons, $p>0.05$. Numbers of cells are indicated above bars.

dal cell inhibitory synapses (Sánchez-Huertas and Rico, 2011). Moreover, exogenous BDNF potentiates glutamatergic synapses onto interneurons in culture (Rutherford et al., 1998). Thus, persistent synaptic plasticity at interneuron excitatory synapses could involve CREB-dependent BDNF transcription and downstream mechanisms.

The requirement for ERK signaling in CREB activation, c-fos

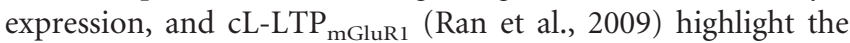
importance of ERK in coupling synaptic activity, transcription, and synaptic plasticity. ERK signaling targets multiple transcription control pathways in addition to CREB (Yoon and Seger, 2006). ERK targets both Elk-1 and CREB in LTP-dependent transcription in dentate gyrus (Davis et al., 2000). The immediate early gene Homer-1a, encoding a scaffolding protein implicated in mGluR1/5 signaling (Xiao et al., 1998), is also upregulated via ERK in granule cells during LTP (Rosenblum et al., 2002) and in pyramidal cells during exploration (Marrone et al., 2008). Thus ERK signaling could target Elk-1 in control of serum response element- 
A

Induction

$3 \times$ mGluR1 stimulation

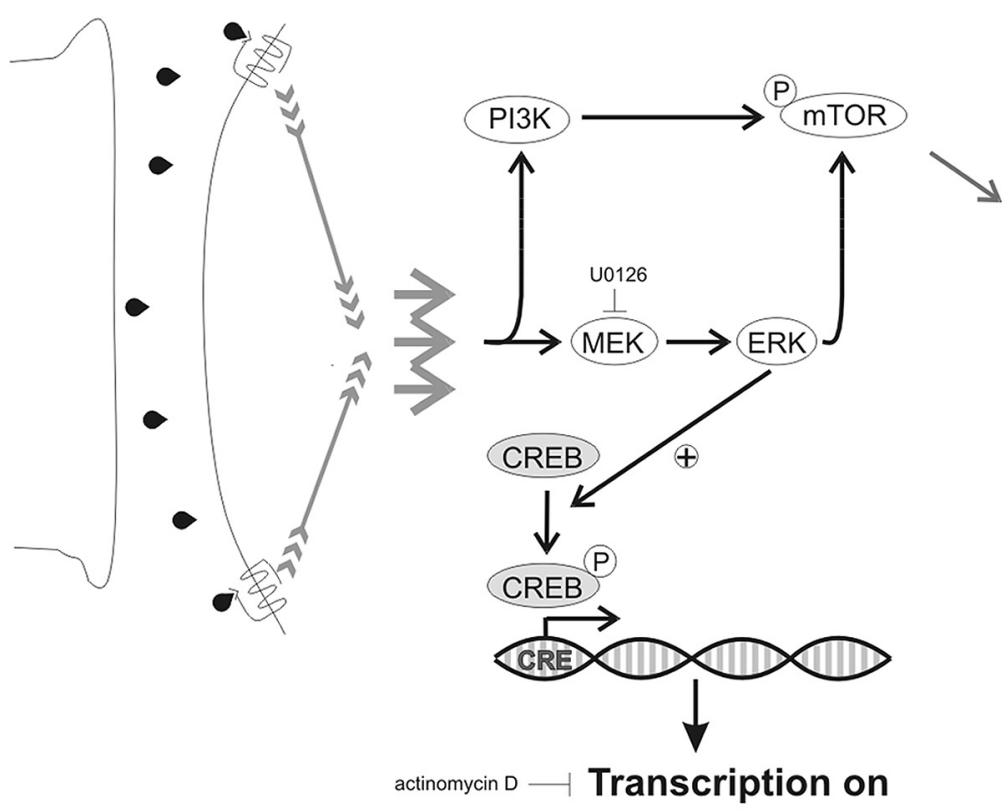

Removal of 4E-BP repressor

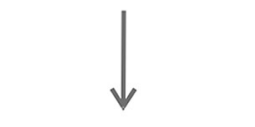

Formation of 4F translation

initiation

complex<smiles>C=CC</smiles>

Translation on

B

Expression

$24 \mathrm{~h}$ post induction

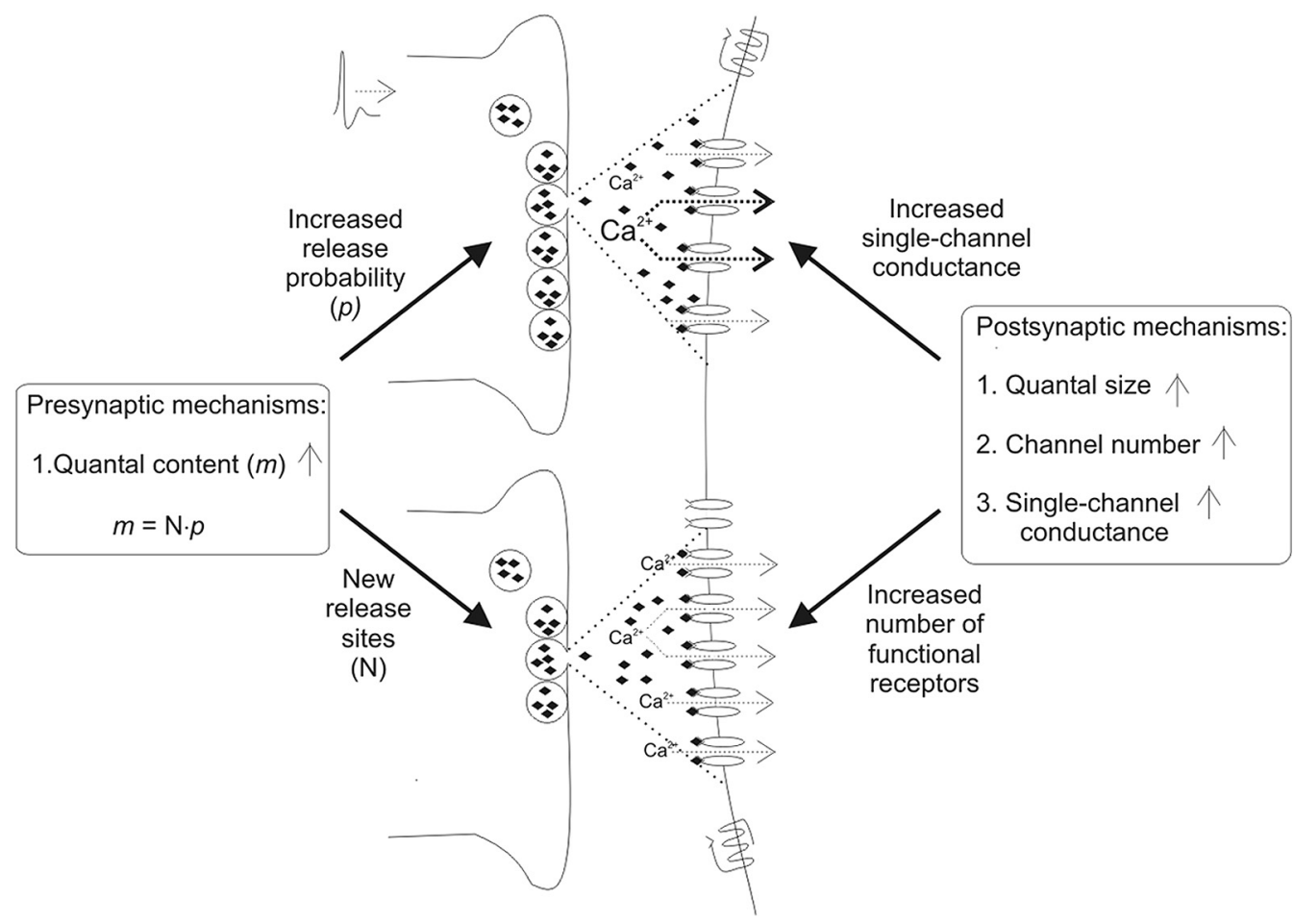

\section{- Glutamate - DHPG UJ CP-non-NMDAR $\widetilde{M}$ mGluR1a}

Figure 9. Induction and expression mechanisms of $\mathrm{CL}_{\mathrm{L}} \mathrm{LTP} \mathrm{mGluR1}_{1}$ at $\mathrm{OA}-\mathrm{IN}$ excitatory synapses. $A$, , CREB-dependent transcriptional control during induction. Summary diagram of transcriptional control based on the observed effects of the MEK-ERK inhibitor, transcription inhibitor, CREB siRNA knockdown, and CREB overexpression on assays of pCREB, CREB-dependent gene expression ( $\left(-\right.$-fos), and CL-LTP ${ }_{\text {mGluR1 } 1}$ in OA-INs. Repeated mGluR1 stimulation activates (1) PI3K, and ERK-signaling pathways converging on mTOR to control cap-dependent translation (Figure legend continues.) 
mediated transcription or Homer-1 1 a transcription and $\mathrm{mGluR} 1 \alpha$ regulation in interneuron persistent synaptic plasticity.

\section{Quantal changes in CL-LTP mGluR $1_{1}$}

The increases in quantal content and size during $\mathrm{CL}-\mathrm{LTP}_{\mathrm{mGluR} 1}$ reflect coordinated presynaptic and postsynaptic changes in synaptic efficacy that are transcription dependent and maintain persistent synaptic plasticity. The change in quantal content was similar to that reported during pyramidal cell L-LTP (Bolshakov et al., 1997) and consistent with recruitment of new functional synaptic contacts (Bozdagi et al., 2000). The probability of release at presynaptic terminals may also be increased during cL$\mathrm{LTP}_{\mathrm{mGluR} 1}$, resulting in multiquantal release from previously silent release sites (Bolshakov et al., 1997). This mechanism is consistent with multiple functional release sites with low-release probability, each releasing a single quantum, at OA-IN glutamatergic synapses (Biró et al., 2005) and with the decrease in PPR during CL-LTP ${ }_{\text {mGluR1 }}$ (Ran et al., 2009; present study). Moreover, the number of release sites determined by quantal analysis agrees with that of contact sites determined anatomically in paired recordings (Biró et al., 2005; Fig. 5A). Interestingly in pyramidal cells, PPR, reflecting presynaptic release probability, is unaltered during L-LTP (Bolshakov et al., 1997), suggesting different maintenance mechanisms in these cells. Multiquantal release could also be due to unmasking of silent synapses by functional recruitment of postsynaptic non-NMDA receptors during CL-LTP mGluR1 $_{\text {(Liao et al., }}$ 1995). However, such unmasking should alter the EPSC NMDA/nonNMDA receptor ratio (Isaac et al., 1995) which was unaffected in cL$\mathrm{LTP}_{\mathrm{mGluR} 1}$. Hence, recruitment of new synaptic contacts or unveiling of silent release sites are plausible presynaptic mechanisms for increased quantal content during cL-LTP mGluR1 $_{\text {. }}$

The increase in quantal size determined by quantal analysis is consistent with the increase in single-channel conductance and functional receptor number obtained from nonstationary fluctuation analysis. In pyramidal cells, modulation of single-channel conductance (Benke et al., 1998) and receptor insertion (Liao et al., 1995) contribute to early LTP but not to L-LTP (Bolshakov et al., 1997), further highlighting differences in expression mechanisms of persistent synaptic plasticity between these cells. Interneurons appear to lack the kinase $\alpha-\mathrm{Ca}^{2+} /$ calmodulin kinase II ( $\alpha$-CaMKII) (Sik et al., 1998) which is implicated in modulating AMPA receptor (AMPAR) channel conductance (Poncer et al., 2002) and trafficking (Andrasfalvy and Magee, 2004) in pyramidal neuron LTP, thus suggesting that interneurons may engage other transduction mechanisms in persistent synaptic plasticity. Such mechanisms may involve a slow direct $\alpha$-CaMKIIindependent Ras/ERK signaling to CREB as demonstrated in hippocampal pyramidal neurons (Wu et al., 2001). Alternatively, other CaMK proteins upstream of ERK, such as CaMK-I and CaMK-kinase, may play a role in CREB-dependent AMPAR channel modulation, especially given their ability to increase channel conductance (Guire et al., 2008) and gate ERK-mediated

\section{$\leftarrow$}

(Figure legend continued.) initiation (Ran et al., 2009) and (2) pCREB via MEK-ERK signaling to control CREB-dependent gene expression. B, Quantal changes during expression. Summary diagram based on quantal and nonstationary fluctuation analyses of synaptic transmission during CL-LTP ${ }_{\text {mGluR1. }}$. A presynaptic action potential releases glutamate which activates $\mathrm{Ca}^{2+}$ permeable non-NMDA receptors generating an EPSC. At $24 \mathrm{~h}$ postinduction, presynaptic and postsynaptic mechanisms increase synaptic efficacy by increasing (1) presynaptic transmitter release (addition of functional release site and/or increase in release probability) and (2) postsynaptic responsiveness (recruitment of functional receptors and increase single-channel channel conductance). translation-dependent pyramidal neuron L-LTP (Schmitt et al., 2005). However, the role of these specific mechanisms in interneuron plasticity remains to be established.

Gating and trafficking of AMPARs is regulated by transmembrane AMPAR regulatory-proteins (TARPs) in pyramidal neurons (Kato et al., 2010). TARP gamma-8 is present at interneuron excitatory synapses (Fukaya et al., 2006), indicating a possible role of TARPs in receptor modulation in CL-LTP ${ }_{\text {mGluR1 }}$. Singlechannel conductance estimates in control $(\sim 15 \mathrm{pS})$ and during cL-LTP ${ }_{\text {mGluR } 1}(\sim 30 \mathrm{pS})$ are close to $\mathrm{Ca}^{2+}$-permeable AMPAR channel values in cerebellar stellate cells (10-35 pS) and are consistent with TARP modulation of recombinant AMPAR channel conductance (Soto et al., 2007). In recombinant channels TARPs also regulate polyamine sensitivity altering rectification (Soto et al., 2007); however, EPSC rectification ratio was unaltered in cL-LTP ${ }_{\text {mGluR } 1}$.

Nonstationary fluctuation analysis revealed a recruitment of

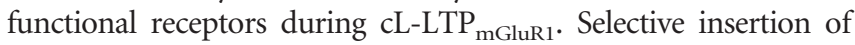
postsynaptic non-NMDA receptors (Liao et al., 1995) is unlikely to be involved since the NMDA/non-NMDA receptor ratio of EPSCs

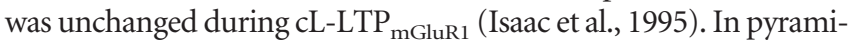
dal cells, synthesis of the constitutively active protein kinase $\mathrm{M} \zeta$ (PKM $\zeta$ ) is implicated in L-LTP maintenance (Yao et al., 2008) by promoting insertion of GluA2-containing $\mathrm{Ca}^{2+}$-impermeable AMPARs (Ling et al., 2006). Since GluA2-lacking $\mathrm{Ca}^{2+}$-permeable AMPAR insertion may be similarly regulated (Newpher and Ehlers, 2008), PKM $\zeta$ could mediate non-NMDAR insertion in cL$\mathrm{LTP}_{\mathrm{mGluR} 1}$ maintenance. Finally, quantal size may also be altered in pyramidal cells by presynaptic mechanisms like regulation of vesicle transmitter content (Edwards, 2007) or vesicle fusion process (Choi et al., 2000). Given that receptor occupancy may not be saturated at OA-IN excitatory synapses (Biró et al., 2005), such a rise in glutamate release and cleft concentration may increase quantal size in

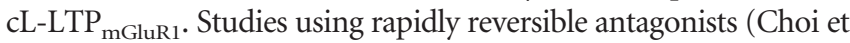
al., 2000) could clarify if glutamate cleft concentration changes dur-

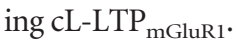

Presynaptic and postsynaptic changes observed here provide evidence of distributed mechanisms during maintenance of persistent synaptic plasticity in inhibitory circuits. Whereas translational and transcriptional control mechanisms in long-term synaptic plasticity appear conserved in the pyramidal cell and interneuron, synaptic changes underlying maintenance differ, indicating a cell type-specific coupling of transcriptional and translational control to expression mechanisms.

\section{Implication for hippocampal function}

Long-term synaptic plasticity in interneurons has been linked to hippocampal-dependent memory (Ruediger et al., 2011). Following contextual and spatial learning, mossy fibers form new synaptic contacts onto CA3 interneurons. The increased connectivity constrains the population of CA3 neurons activated, suppresses generalization, and yields precision of learning-related hippocampal spatial memories (Ruediger et al., 2011). In NF1 mutant mice, selective mutation of neurofibromin in interneurons produces ERK-mediated increases in GABA release, and impairs hippocampal LTP and learning (Cui et al., 2008). Moreover, spatial learning triggers ERK signaling in interneurons and a lasting increase in pyramidal cell synaptic inhibition (Cui et al., 2008). This role of inhibitory interneuron synaptic plasticity in the constraint of pyramidal cell LTP and generalization is consistent with biophysical simulations of learned pattern recognition in CA1 neuronal networks (Grunze et al., 1996). We propose that the mechanisms of persistent synaptic plasticity uncovered here 
could play a role in constraining pyramidal cell ensembles recruited during learning, as well as pyramidal cell LTP, thereby contributing to memory precision.

A critical role of interneurons in hippocampal LTP and memory is also supported by evidence that mGluR1s are highly expressed in interneurons compared with pyramidal cells (Baude et al., 1993) and that mGluR1 knock-out mice display impaired Schaffer collateral LTP and contextual learning (Aiba et al., 1994). Also, mGluR1 blockade in CA1 hippocampus disrupts inhibitory avoidance learning (Simonyi et al., 2007). Hence, interneuron mGluR1 function is likely contributing to these synaptic and behavioral impairments. Moreover, deletion of HCN2 channels in interneurons reduces interneuron excitability and pyramidal cell inhibition, and augments LTP in the temporoammonic pathway (Matt et al., 2010), also supporting a role in constraining LTP. Thus, mechanisms of persistent synaptic plasticity uncovered here could serve to regulate activity and plasticity in pyramidal cell input pathways. Finally, recordings in freely moving rats indicate that hippocampal pyramidal neuron-interneuron pairs form both positively and negatively correlated place maps suggesting that interneurons do not simply replicate spatial maps of their pyramidal neuron counterpart (Marshall et al., 2002) but also encode complementary maps (Hangya et al., 2010). Persistent synaptic plasticity at pyramidal cell-interneuron synapses could potentially modify transfer of place-field attributes from upstream pyramidal neurons, and thus allow interneurons to encode spatial representations.

\section{References}

Abel T, Nguyen PV, Barad M, Deuel TA, Kandel ER, Bourtchouladze R (1997) Genetic demonstration of a role for PKA in the late phase of LTP and in hippocampus-based long-term memory. Cell 88:615-626.

Aiba A, Chen C, Herrup K, Rosenmund C, Stevens CF, Tonegawa S (1994) Reduced hippocampal long-term potentiation and context-specific deficit in associative learning in mGluR1 mutant mice. Cell 79:365-375.

Andrásfalvy BK, Magee JC (2004) Changes in AMPA receptor currents following LTP induction on rat CA1 pyramidal neurones. J Physiol 559:543-554.

Banko JL, Poulin F, Hou L, DeMaria CT, Sonenberg N, Klann E (2005) The translation repressor 4E-BP2 is critical for eIF4F complex formation, synaptic plasticity, and memory in the hippocampus. J Neurosci 25:9581-9590.

Barco A, Alarcon JM, Kandel ER (2002) Expression of constitutively active CREB protein facilitates the late phase of long-term potentiation by enhancing synaptic capture. Cell 108:689-703.

Barco A, Patterson SL, Alarcon JM, Gromova P, Mata-Roig M, Morozov A, Kandel ER (2005) Gene expression profiling of facilitated L-LTP in VP16-CREB mice reveals that BDNF is critical for the maintenance of LTP and its synaptic capture. Neuron 48:123-137.

Baude A, Nusser Z, Roberts JD, Mulvihill E, McIlhinney RA, Somogyi P (1993) The metabotropic glutamate receptor (mGluR1 alpha) is concentrated at perisynaptic membrane of neuronal subpopulations as detected by immunogold reaction. Neuron 11:771-787.

Benke TA, Lüthi A, Isaac JT, Collingridge GL (1998) Modulation of AMPA receptor unitary conductance by synaptic activity. Nature 393:793-797.

Biró AA, Holderith NB, Nusser Z (2005) Quantal size is independent of the release probability at hippocampal excitatory synapses. J Neurosci 25:223-232.

Bolshakov VY, Golan H, Kandel ER, Siegelbaum SA (1997) Recruitment of new sites of synaptic transmission during the cAMP-dependent late phase of LTP at CA3-CA1 synapses in the hippocampus. Neuron 19:635-651.

Bourdeau ML, Morin F, Laurent CE, Azzi M, Lacaille JC (2007) Kv4.3mediated A-type $\mathrm{K}+$ currents underlie rhythmic activity in hippocampal interneurons. J Neurosci 27:1942-1953.

Bourtchuladze R, Frenguelli B, Blendy J, Cioffi D, Schutz G, Silva AJ (1994) Deficient long-term memory in mice with a targeted mutation of the cAMP-responsive element-binding protein. Cell 79:59-68.

Bozdagi O, Shan W, Tanaka H, Benson DL, Huntley GW (2000) Increasing numbers of synaptic puncta during late-phase LTP: N-cadherin is synthesized, recruited to synaptic sites, and required for potentiation. Neuron 28:245-259.

Choi S, Klingauf J, Tsien RW (2000) Postfusional regulation of cleft glutamate concentration during LTP at 'silent synapses'. Nat Neurosci 3:330-336

Croce A, Pelletier JG, Tartas M, Lacaille JC (2010) Afferent-specific properties of interneuron synapses underlie selective long-term regulation of feedback inhibitory circuits in CA1 hippocampus. J Physiol 588:20912107.

Cui Y, Costa RM, Murphy GG, Elgersma Y, Zhu Y, Gutmann DH, Parada LF, Mody I, Silva AJ (2008) Neurofibromin regulation of ERK signaling modulates GABA release and learning. Cell 135:549-560.

Davis S, Vanhoutte P, Pages C, Caboche J, Laroche S (2000) The MAPK/ ERK cascade targets both Elk-1 and cAMP response element-binding protein to control long-term potentiation-dependent gene expression in the dentate gyrus in vivo. J Neurosci 20:4563-4572.

Del Castillo J, Katz B (1954) Quantal components of the end-plate potential. J Physiol 124:560-573.

Durand GM, Marandi N, Herberger SD, Blum R, Konnerth A (2006) Quantitative single-cell RT-PCR and Ca2+ imaging in brain slices. Pflugers Arch 451:716-726.

Edwards RH (2007) The neurotransmitter cycle and quantal size. Neuron 55:835-858.

Fukaya M, Tsujita M, Yamazaki M, Kushiya E, Abe M, Akashi K, Natsume R, Kano M, Kamiya H, Watanabe M, Sakimura K (2006) Abundant distribution of TARP gamma-8 in synaptic and extrasynaptic surface of hippocampal neurons and its major role in AMPA receptor expression on spines and dendrites. Eur J Neurosci 24:2177-2190.

Gonzalez GA, Montminy MR (1989) Cyclic AMP stimulates somatostatin gene transcription by phosphorylation of CREB at serine 133. Cell 59:675-680.

Grunze HC, Rainnie DG, Hasselmo ME, Barkai E, Hearn EF, McCarley RW, Greene RW (1996) NMDA-dependent modulation of CA1 local circuit inhibition. J Neurosci 16:2034-2043.

Guire ES, Oh MC, Soderling TR, Derkach VA (2008) Recruitment of calcium-permeable AMPA receptors during synaptic potentiation is regulated by CaM-kinase I. J Neurosci 28:6000-6009.

Guzowski JF, McGaugh JL (1997) Antisense oligodeoxynucleotidemediated disruption of hippocampal cAMP response element binding protein levels impairs consolidation of memory for water maze training. Proc Natl Acad Sci U S A 94:2693-2698.

Han JH, Kushner SA, Yiu AP, Cole CJ, Matynia A, Brown RA, Neve RL, Guzowski JF, Silva AJ, Josselyn SA (2007) Neuronal competition and selection during memory formation. Science 316:457-460.

Hangya B, Li Y, Muller RU, Czurkó A (2010) Complementary spatial firing in place cell-interneuron pairs. J Physiol 588:4165-4175.

Hartveit E, Veruki ML (2007) Studying properties of neurotransmitter receptors by non-stationary noise analysis of spontaneous postsynaptic currents and agonist-evoked responses in outside-out patches. Nat Protoc 2:434-448.

Hong EJ, McCord AE, Greenberg ME (2008) A biological function for the neuronal activity-dependent component of Bdnf transcription in the development of cortical inhibition. Neuron 60:610-624.

Impey S, Obrietan K, Wong ST, Poser S, Yano S, Wayman G, Deloulme JC, Chan G, Storm DR (1998) Cross talk between ERK and PKA is required for Ca2 + stimulation of CREB-dependent transcription and ERK nuclear translocation. Neuron 21:869-883.

Isaac JT, Nicoll RA, Malenka RC (1995) Evidence for silent synapses: implications for the expression of LTP. Neuron 15:427-434.

Kaang BK, Kandel ER, Grant SG (1993) Activation of cAMP-responsive genes by stimuli that produce long-term facilitation in Aplysia sensory neurons. Neuron 10:427-435.

Kato AS, Gill MB, Yu H, Nisenbaum ES, Bredt DS (2010) TARPs differentially decorate AMPA receptors to specify neuropharmacology. Trends Neurosci 33:241-248.

Klausberger T, Somogyi P (2008) Neuronal diversity and temporal dynamics: the unity of hippocampal circuit operations. Science 321:53-57.

Kullmann DM, Lamsa KP (2007) Long-term synaptic plasticity in hippocampal interneurons. Nat Rev Neurosci 8:687-699.

Lapointe V, Morin F, Ratté S, Croce A, Conquet F, Lacaille JC (2004) Synapse-specific mGluR1-dependent long-term potentiation in in- 
terneurones regulates mouse hippocampal inhibition. J Physiol 555: $125-135$.

Lee YS, Silva AJ (2009) The molecular and cellular biology of enhanced cognition. Nat Rev Neurosci 10:126-140.

Liao D, Hessler NA, Malinow R (1995) Activation of postsynaptically silent synapses during pairing-induced LTP in CA1 region of hippocampal slice. Nature 375:400-404.

Ling DS, Benardo LS, Sacktor TC (2006) Protein kinase Mzeta enhances excitatory synaptic transmission by increasing the number of active postsynaptic AMPA receptors. Hippocampus 16:443-452.

Liu SQ, Cull-Candy SG (2000) Synaptic activity at calcium-permeable AMPA receptors induces a switch in receptor subtype. Nature 405:454458.

Marrone DF, Schaner MJ, McNaughton BL, Worley PF, Barnes CA (2008) Immediate-early gene expression at rest recapitulates recent experience. J Neurosci 28:1030-1033.

Marshall L, Henze DA, Hirase H, Leinekugel X, Dragoi G, Buzsáki G (2002) Hippocampal pyramidal cell-interneuron spike transmission is frequency dependent and responsible for place modulation of interneuron discharge. J Neurosci 22:RC197.

Martin SJ, Grimwood PD, Morris RG (2000) Synaptic plasticity and memory: an evaluation of the hypothesis. Annu Rev Neurosci 23:649-711.

Matt L, Michalakis S, Hofmann F, Hammelmann V, Ludwig A, Biel M, Kleppisch T (2010) HCN2 channels in local inhibitory interneurons constrain LTP in the hippocampal direct perforant path. Cell Mol Life Sci.

McBain CJ, Kauer JA (2009) Presynaptic plasticity: targeted control of inhibitory networks. Curr Opin Neurobiol 19:254-262.

Milner B, Squire LR, Kandel ER (1998) Cognitive neuroscience and the study of memory. Neuron 20:445-468.

Newpher TM, Ehlers MD (2008) Glutamate receptor dynamics in dendritic microdomains. Neuron 58:472-497.

Perez Y, Morin F, Lacaille JC (2001) A hebbian form of long-term potentiation dependent on mGluRla in hippocampal inhibitory interneurons. Proc Natl Acad Sci U S A 98:9401-9406.

Poncer JC, Esteban JA, Malinow R (2002) Multiple mechanisms for the potentiation of AMPA receptor-mediated transmission by alpha- $\mathrm{Ca}^{2+}$ / calmodulin-dependent protein kinase II. J Neurosci 22:4406-4411.

Ran I, Laplante I, Bourgeois C, Pépin J, Lacaille P, Costa-Mattioli M, Pelletier J, Sonenberg N, Lacaille JC (2009) Persistent transcription- and translation-dependent long-term potentiation induced by mGluR1 in hippocampal interneurons. J Neurosci 29:5605-5615.

Redman S (1990) Quantal analysis of synaptic potentials in neurons of the central nervous system. Physiol Rev 70:165-198.

Rosenblum K, Futter M, Voss K, Erent M, Skehel PA, French P, Obosi L, Jones MW, Bliss TV (2002) The role of extracellular regulated kinases I/II in late-phase long-term potentiation. J Neurosci 22:5432-5441.

Ruediger S, Vittori C, Bednarek E, Genoud C, Strata P, Sacchetti B, Caroni P (2011) Learning-related feedforward inhibitory connectivity growth required for memory precision. Nature 473:514-518.
Rutherford LC, Nelson SB, Turrigiano GG (1998) BDNF has opposite effects on the quantal amplitude of pyramidal neuron and interneuron excitatory synapses. Neuron 21:521-530.

Sánchez-Huertas C, Rico B (2011) CREB-Dependent Regulation of GAD65 Transcription by BDNF/TrkB in Cortical Interneurons. Cereb Cortex 21:777-788.

Schmitt JM, Guire ES, Saneyoshi T, Soderling TR (2005) Calmodulin-dependent kinase kinase/calmodulin kinase I activity gates extracellular-regulated kinasedependent long-term potentiation. J Neurosci 25:1281-1290.

Sheng M, McFadden G, Greenberg ME (1990) Membrane depolarization and calcium induce c-fos transcription via phosphorylation of transcription factor CREB. Neuron 4:571-582.

Shi SH, Hayashi Y, Petralia RS, Zaman SH, Wenthold RJ, Svoboda K, Malinow R (1999) Rapid spine delivery and redistribution of AMPA receptors after synaptic NMDA receptor activation. Science 284:1811-1816.

Sik A, Hájos N, Gulácsi A, Mody I, Freund TF (1998) The absence of a major $\mathrm{Ca} 2+$ signaling pathway in GABAergic neurons of the hippocampus. Proc Natl Acad Sci U S A 95:3245-3250.

Simonyi A, Serfozo P, Shelat PB, Dopheide MM, Coulibaly AP, Schachtman TR (2007) Differential roles of hippocampal metabotropic glutamate receptors 1 and 5 in inhibitory avoidance learning. Neurobiol Learn Mem 88:305-311.

Soto D, Coombs ID, Kelly L, Farrant M, Cull-Candy SG (2007) Stargazin attenuates intracellular polyamine block of calcium-permeable AMPA receptors. Nat Neurosci 10:1260-1267.

Tamamaki N, Yanagawa Y, Tomioka R, Miyazaki J, Obata K, Kaneko T (2003) Green fluorescent protein expression and colocalization with calretinin, parvalbumin, and somatostatin in the GAD67-GFP knock-in mouse. J Comp Neurol 467:60-79.

Tully T, Bourtchouladze R, Scott R, Tallman J (2003) Targeting the CREB pathway for memory enhancers. Nat Rev Drug Discov 2:267-277.

West AE, Griffith EC, Greenberg ME (2002) Regulation of transcription factors by neuronal activity. Nat Rev Neurosci 3:921-931.

Wu GY, Deisseroth K, Tsien RW (2001) Activity-dependent CREB phosphorylation: convergence of a fast, sensitive calmodulin kinase pathway and a slow, less sensitive mitogen-activated protein kinase pathway. Proc Natl Acad Sci U S A 98:2808-2813.

Xiao B, Tu JC, Petralia RS, Yuan JP, Doan A, Breder CD, Ruggiero A, Lanahan AA, Wenthold RJ, Worley PF (1998) Homer regulates the association of group 1 metabotropic glutamate receptors with multivalent complexes of homer-related, synaptic proteins. Neuron 21:707-716.

Yao Y, Kelly MT, Sajikumar S, Serrano P, Tian D, Bergold PJ, Frey JU, Sacktor TC (2008) PKM zeta maintains late long-term potentiation by $\mathrm{N}$-ethylmaleimide-sensitive factor/GluR2-dependent trafficking of postsynaptic AMPA receptors. J Neurosci 28:7820-7827.

Yin JC, Tully T (1996) CREB and the formation of long-term memory. Curr Opin Neurobiol 6:264-268.

Yoon S, Seger R (2006) The extracellular signal-regulated kinase: multiple substrates regulate diverse cellular functions. Growth Factors 24:21-44. 